\title{
RESEARCH
}

Open Access

\section{Diagnostic and prognostic value of plasma neurofilament light and total-tau in sporadic Creutzfeldt-Jakob disease}

Inga Zerr ${ }^{1,2}$, Anna Villar-Piqué ${ }^{3,4}$, Peter Hermann ${ }^{1 *}$, Matthias Schmitz ${ }^{1,2}$, Daniela Varges ${ }^{1}$, Isidre Ferrer ${ }^{3,4,5}$, Joachim Riggert ${ }^{6}$, Henrik Zetterberg ${ }^{7,8,9,10}$, Kaj Blennow ${ }^{7,8}$ and Franc Llorens ${ }^{1,3,4^{*}}$

\begin{abstract}
Background: Blood neurofilament light ( $\mathrm{Nfl}$ ) and total-tau (t-tau) have been described to be increased in several neurological conditions, including prion diseases and other neurodegenerative dementias. Here, we aim to determine the accuracy of plasma $\mathrm{Nfl}$ and t-tau in the differential diagnosis of neurodegenerative dementias and their potential value as prognostic markers of disease severity.

Methods: Plasma Nfl and t-tau were measured in healthy controls $(\mathrm{HC}, n=70)$, non-neurodegenerative neurological disease with (NND-Dem, $n=17)$ and without dementia syndrome (NND, $n=26)$, Alzheimer's disease $(A D, n=44)$, Creutzfeldt-Jakob disease (CJD, $n=83)$, dementia with Lewy bodies/Parkinson's disease with dementia (DLB/PDD, $n=$ 35), frontotemporal dementia (FTD, $n=12)$, and vascular dementia $(\mathrm{VaD}, n=22)$. Biomarker diagnostic accuracies and cutoff points for the diagnosis of CJD were calculated, and associations between $\mathrm{Nfl}$ and t-tau concentrations with other fluid biomarkers, demographic, genetic, and clinical data in CJD cases were assessed. Additionally, the value of $\mathrm{Nfl}$ and t-tau predicting disease survival in CJD was evaluated.

Results: Among diagnostic groups, highest plasma Nfl and t-tau concentrations were detected in CJD (fold changes of 38 and 18, respectively, compared to HC). Elevated t-tau was able to differentiate CJD from all other groups, whereas elevated Nfl concentrations were also detected in NND-Dem, AD, DLB/PDD, FTD, and VaD compared to HC. Both biomarkers discriminated CJD from non-CJD dementias with an AUC of 0.93. In CJD, plasma t-tau, but not Nfl, was associated with PRNP codon 129 genotype and CJD subtype. Positive correlations were observed between plasma Nfl and t-tau concentrations, as well as between plasma and CSF concentrations of both biomarkers $(p<0.001)$. Nfl was increased in rapidly progressive AD (rpAD) compared to slow progressive AD (spAD) and associated to Mini-Mental State Examination results. However, Nfl displayed higher accuracy than t-tau discriminating CJD from rpAD and spAD. Finally, plasma t-tau, but not plasma Nfl, was significantly associated with disease duration, offering a moderate survival prediction capacity.

(Continued on next page)
\end{abstract}

\footnotetext{
* Correspondence: peter.hermann@med.uni-goettingen.de;

franc.llorens@gmail.com

${ }^{1}$ Department of Neurology, National Reference Center for TSE Surveillance, University Medical Center, Robert-Koch Street 40, Göttingen, Germany

Full list of author information is available at the end of the article
}

(c) The Author(s). 2021 Open Access This article is licensed under a Creative Commons Attribution 4.0 International License, which permits use, sharing, adaptation, distribution and reproduction in any medium or format, as long as you give appropriate credit to the original author(s) and the source, provide a link to the Creative Commons licence, and indicate if changes were made. The images or other third party material in this article are included in the article's Creative Commons licence, unless indicated otherwise in a credit line to the material. If material is not included in the article's Creative Commons licence and your intended use is not permitted by statutory regulation or exceeds the permitted use, you will need to obtain permission directly from the copyright holder. To view a copy of this licence, visit http://creativecommons.org/licenses/by/4.0/. The Creative Commons Public Domain Dedication waiver (http://creativecommons.org/publicdomain/zero/1.0/) applies to the data made available in this article, unless otherwise stated in a credit line to the data. 
(Continued from previous page)

Conclusions: Plasma Nfl and t-tau are useful complementary biomarkers for the differential diagnosis of CJD.

Additionally, plasma t-tau emerges as a potential prognostic marker of disease duration.

Keywords: Dementia, Creutzfeldt-Jakob disease, Biomarkers, Plasma, Neurofilament light, Tau, Diagnosis, Disease progression

\section{Background}

Neurodegenerative dementias are a group of clinically heterogeneous diseases characterized by gradual progression of cognitive dysfunction, psychiatric and behavioral symptoms, and movement deficits. They can be associated either with the aggregation and accumulation of misfolded proteins (i.e., Alzheimer's disease (AD), fronto-temporal dementia (FTD), dementia with Lewy bodies (DLB), Parkinson's disease dementia (PDD), and CreutzfeldtJakob disease (CJD)) or with brain damage due to impaired blood flow, leading to vascular dementia $(\mathrm{VaD})$.

The presence of overlapping symptomatology in neurodegenerative dementias is frequent, thus differential diagnosis, currently based on clinical evaluation and biological and topological markers, may be challenging [1-3]. Cerebrospinal fluid (CSF)-based tests for total-tau (t-tau), phospho-tau (ptau) and amyloid $\beta(\mathrm{A} \beta 42)$ are included in the diagnostic criteria of $\mathrm{AD}$ [4], while 14-3-3 protein and $\mathrm{PrP}^{\mathrm{Sc}}$ detection by the real-time quacking induced conversion (RT-QuIC) are included in the diagnostic criteria of CJD $[5,6]$. Other CSF biomarkers such as neurofilament light $(\mathrm{Nfl})$ are increased in the CSF of all neurodegenerative dementias studied, as well as in motor neuron diseases, being considered as a general marker of neurodegeneration. Its low specificity undermines its potential use in the differential diagnostic context, but favors its use to identify and grade, or exclude, neurodegeneration. In addition, the observation that $\mathrm{Nfl}$ is associated to survival and disease severity in many neurodegenerative conditions suggests a potential role as dynamic and prognostic marker [7-9].

Blood-based biomarkers offer important advantages over CSF-based biomarkers. In contrast to lumbar puncture, blood collection is time- and cost-effective and can be easily obtained in primary care. Thus, development of blood-based assays may lead to the implementation of non-invasive front-line tests for early diagnosis, screening of populations, and follow-up analysis of patients (disease monitoring). Despite the potential advantages of blood biomarkers, the low concentrations of brainderived biomarkers in blood impeded their study and validation as robust biomarkers until the recent development of antibody-based ultrasensitive technologies [10]. In this regard, alterations of brain biomarkers in blood have been recently reported in several neurodegenerative dementias. Nfl and t-tau are two of the most promising ones to be translated into clinical grounds regarding their diagnostic and prognostic value, especially in CJD, where both proteins are highly increased compared with controls and other neurodegenerative diseases [11-16]. Since $\mathrm{Nfl}$ and $\mathrm{t}$-tau are associated with neuronal damage, a common hallmark in neurodegenerative dementias, it is crucial to determine their specificity and accuracy in the differential diagnostic context.

The main objective of this study was to validate previous observations on the diagnostic accuracy of plasma $\mathrm{Nfl}$ and t-tau in CJD with additional consideration of relevant non-neurodegenerative and neurodegenerative differential diagnoses such as rapidly progressive AD (rpAD). Further, we investigated plasma Nfl and t-Tau in CJD-subtypes, associations with other known CJD-biomarkers, influence of disease stage, and prognostic values. Finally, we compared the diagnostic and prognostic accuracy of both biomarkers between plasma and CSF.

\section{Methods \\ Study design, population, and data acquisition}

Data and samples were collected in the framework of a prospective study on CJD surveillance and diagnostics. For this retrospective analysis, we utilized the clinical database and the biobank of the German National Reference Center for Transmissible Spongiform Encephalopathies. CJD cases were selected on the base of availability of plasma samples, clinical information, and sufficient diagnostic characterization. The clinical and demographic information had been recorded during the diagnostic process through a standardized questionnaire including a third-party anamnesis. Samples from neurological disease control groups and neurodegenerative dementias were obtained at the Department of Neurology of the University Medical Center and the National Reference Center for Creutzfeldt-Jakob disease and healthy controls $(\mathrm{HC})$ at the Department of Transfusion Medicine, University Medical Center Göttingen (Germany). A total of 309 plasma samples were used in this study. Blood was collected in EDTA tubes and centrifuged at $1500 \times g$ and $4{ }^{\circ} \mathrm{C}$ for 10 min under same pre-analytical conditions. CSF sampling in CJD cases was performed at the same day as blood uptake or up to a maximum of 15 days earlier.

\section{Case and sample characterization}

The healthy control (HC) group was composed of healthy blood donors with absence of any relevant 
clinical findings. The neurological disease control group was composed of cases diagnosed with neurological conditions either without (NND) or with cognitive impairment or dementia at the time of sampling (NND-Dem). NDD-Dem cases were initially suspected of CJD ("CJDmimics") but prion diseases were subsequently excluded. NND and NND-Dem cases were diagnosed according to acknowledged standard neurologic clinical and paraclinical findings based on the ICD 10 definitions. The NND group included the following diagnostic groups: epilepsy, psychiatric disorders, headache, hypoxia, cerebral lymphoma, paraneoplasia, vertigo, vascular encephalopathy, and pain syndromes, while the NND-Dem group included cerebral vasculitis, normal-pressure hydrocephalus, Wilson's disease, CNS neoplasia, encephalitis, ischemic stroke, and dementia due to alcohol abuse. Alzheimer's disease (AD) was diagnosed according to the National Institute on Aging - Alzheimer's Association workgroups (NIA-AA) criteria [4]. Stratification of $\mathrm{AD}$ cases in slow progressive $\mathrm{AD}$ (spAD), and rapid progressive $\mathrm{AD}$ (rpAD) was based on rate of cognitive decline. Rapid progression was defined by a cognitive decline of more than 6 points per year on the Mini Mental Status Examination (MMSE) scale. Cases with no rapid progression 1 year before or after blood collection were classified as rpAD. Velocity of decline was calculated using linear regression (least square method) as described before [17]. Sporadic Creutzfeldt-Jakob disease (CJD) cases were diagnosed according to consensus criteria in either probable (clinical diagnosis, $n=15$ ) or definite (neuropathological confirmation, $n=68$ ) [6]. Diagnosis of dementia with Lewy bodies (DLB) was based on the criteria of McKeith [18]; Parkinson's disease dementia (PDD) diagnosis was based on the task force of the Movement Disorder Society criteria [19] and differentiated from other Parkinson-plus syndromes using established diagnostic criteria for corticobasal degeneration [20], progressive supranuclear palsy [21], and multiple system atrophy [22]. Fronto-temporal dementia (FTD) was diagnosed according to the International Behavioural Variant FTD Criteria Consortium for bvFTD [23]. Vascular dementia (VaD) diagnosis was based on clinical and radiological criteria as described by the (National Institute of Neurological and Communicative Disorders and Stroke and the Alzheimer's Disease and Related Disorders Association) [24]. Relevant copathologies were excluded in all diagnostic groups by clinical criteria and review of the records from the diagnostic work-up, including MRI scans. In the VaD group, CSF p-Tau and beta-amyloid 1-42 were considered to exclude concomitant AD pathology as far as possible.

To calculate the influence of sampling and disease severity in biomarkers concentrations, CJD cases were stratified in three categories according to whether blood was collected in the first, second, or third tertial of the total disease duration. Additionally, CJD cases were classified as early stage, in which at least one clinical hallmark for CJD [6] but no complete loss of communication ability and voluntary movement was present, and late stage, akinetic mutism. To evaluate the prognostic value of plasma $\mathrm{Nfl}$ and $\mathrm{t}$-tau as prognostic markers, disease duration was recorded as the time (in days) from symptom onset or from blood uptake to the death of the patient. Symptom onset was evaluated through a thirdparty questionnaire (wife, spouse, or 1st grade relative) and defined as the date either cognitive, visual, balance, or movement disturbances had become apparent.

\section{Plasma and CSF tests}

Plasma Nfl and total tau levels were measured using commercially available kits on the Single molecule array (Simoa) HD-1 Analyzer (Quanterix). YKL-40 was measured using the MicroVueYKL-40 EIA ELISA kit from Quidel as previously described [25]. Total-Prion protein (t-PrP) was quantified using a fluorometric custom-made ELISA as described before [26]. CSF Nfl and total-tau (t-tau) were quantified using the enzyme-linked immunosorbent assay kits NF-light (UmanDiagnostics) and INNOTEST hTAU-Ag (Fujirebio), respectively. CSF was analyzed for the presence of 14-3-3 protein using western blot [27]. Amyloid $\beta$ (A $\beta 42)$ was measured using the INNOTEST ${ }^{\circ} \beta$-AMYLOID ELISA kit from Fujirebio.

\section{Statistical analysis}

Comparison of mean age between diagnostic groups was performed with ANOVA-test and Tukey correction. Differences in the sex ratio were compared with chisquared test, and $p$ values were adjusted with the Holm method. Comparison of biomarker levels among diagnostic groups was performed with linear regression models. Biomarker data were log-transformed, and age and sex were included as covariates. Multiple comparisons of means were performed with Tukey contrasts, available in the multcomp $R$ package [28]. The same analysis was applied in the investigation of the influence of the PRNP codon 129 genotype and the time of sampling on biomarkers levels. Comparison of biomarker levels in 14-3-3 positive and negative groups was performed using the Mann-Whitney test. Spearman rank coefficients were used to quantify associations between continuous biomarkers levels. To assess the diagnostic accuracy of plasma $\mathrm{Nfl}$ and $\mathrm{t}$-tau, receiver operating characteristic (ROC) curve analyses were carried out and areas under the curve (AUC) with 95\% confidence intervals $(95 \% \mathrm{CI})$ were calculated. AUC values were compared with pROC $\mathrm{R}$ package, using the Bootstrap method [29]. The best cutoff values were estimated based on the Youden index. The CJD cases were 
stratified in two groups based on the duration of the disease: short course (when disease duration from onset was below mean disease duration $=165$ days) or long course (otherwise). Differences on biomarker levels between these two groups were assessed with linear regression models controlling for demographic covariates where the biomarker data were log transformed. Relationship between disease duration and each biomarker was explored with the non-parametric Spearman correlation coefficient and with Cox proportional hazards $(\mathrm{PH})$ models controlling for significant covariates (age, sex, and PRNP codon 129 genotype), using the survival $\mathrm{R}$ package [30]. $\mathrm{PH}$ assumption was tested with the Schoenfeld residuals against the transformed time. To allow for non-linear associations between biomarker data and disease duration, we employed the multivariable fractional polynomial method, using the mfp package in $\mathrm{R}$ [31]. Graphical representation of regression models was performed with visreg $\mathrm{R}$ package [32]. Statistical significance was considered at $p<0.05$.

\section{Results}

\section{Plasma Nfl and t-tau in controls, CJD, and differential diagnoses}

Data on age, sex, and plasma biomarkers for the study cohort are presented in Table 1. No significant differences on age were detected between diagnostic groups. Statistically significant differences in the sex ratio were detected in CJD compared to DLB/PDD $(p=0.04)$ and to $\mathrm{HC}(p=0.0016)$. In $\mathrm{HC}$, mean values of Nfl differed between sexes $($ female $=8.03 \mathrm{pg} / \mathrm{mL}$, male $=9.75 \mathrm{pg} / \mathrm{mL}$ ) with borderline significance $(p=0.044)$ whereas no significant differences were detected for Nfl in CJD and for $\mathrm{t}$-tau in both groups.

The highest Nfl concentrations were detected in CJD followed by NND-Dem, VaD, DLB/PDD, AD, FTD, NND, and HC (Table 1 and Fig. 1a). In a multicomparative analysis corrected for covariates, Nfl concentrations were increased in CJD compared to $\mathrm{HC}$, NND, AD, DLB/PDD, FTD, and $\mathrm{VaD}(p<0.001)$, in $\mathrm{AD}$ compared to $\mathrm{HC}(p<0.001)$ and $\mathrm{NND}(p=0.002)$, in DLB/PDD compared to HC and NND $(p<0.001)$, in FTD compared to HC $(p=0.020)$, and in $\mathrm{VaD}$ compared to $\mathrm{HC}$ and NND $(p<0.001)$. Additionally, significantly higher $\mathrm{Nfl}$ concentrations were observed in NND-Dem compared to HC, NND, AD, DLB/PDD, FTD, and VaD $(p<0.001)$ (Fig. 1a, c). In contrast, $\mathrm{t}$-tau was exclusively increased in CJD, with significantly different concentrations when compared to HC, NND, NND-Dem, AD, DLB/PDD, FTD, and VaD $(p<0.001)$ (Fig. 1b, c).

The diagnostic accuracy of $\mathrm{Nfl}$ and $\mathrm{t}$-tau discriminating the different diagnostic groups was calculated using the areas under the curve (AUC) and 95\% confidence intervals (95\% CI) (Table 2). Nfl was able to differentiate $\mathrm{HC}$ and NND from neurodegenerative dementias with good accuracy (AUC $>0.81$ in all cases, with the exception of the NND vs. FTD comparison, AUC = 0.66). Nfl displayed a remarkable discriminatory value for CJD compared with non-demented controls $(\mathrm{AUC}=1$, vs. $\mathrm{HC}$ and $\mathrm{AUC}=0.97$ vs. NND). High Nfl levels in NNDDem were translated in AUC values ranging from 0.88 to 0.97 discriminating $\mathrm{AD}, \mathrm{DLB} / \mathrm{PDD}$, FTD, and $\mathrm{VaD}$

Table 1 Demographic and biomarkers data from the study population

\begin{tabular}{|c|c|c|c|c|c|c|c|c|}
\hline & \multirow[t]{2}{*}{ n } & \multirow{2}{*}{$\begin{array}{l}\text { Sex } \\
(\mathrm{f} / \mathrm{m})\end{array}$} & \multirow{2}{*}{$\begin{array}{l}\text { Age } \\
\text { (years) }\end{array}$} & \multirow{2}{*}{$\begin{array}{l}\text { Duration } \\
\text { (days)* }^{*}\end{array}$} & \multicolumn{2}{|c|}{ Plasma Nfl (pg/mL) } & \multicolumn{2}{|c|}{ Plasma t-Tau (pg/mL) } \\
\hline & & & & & Mean + SD & $95 \% \mathrm{Cl}$ & Mean + SD & $95 \% \mathrm{Cl}$ \\
\hline \multicolumn{9}{|l|}{ Controls } \\
\hline $\mathrm{HC}$ & 70 & $22 / 48$ & $64.7 \pm 5.1$ & - & $9.2 \pm 3.4$ & $8.4-10.0$ & $2.5 \pm 1.2$ & $2.3-2.8$ \\
\hline NND & 26 & $13 / 13$ & $64.1 \pm 6.9$ & - & $23.4 \pm 39.6$ & $7.4-39.5$ & $3.7 \pm 2.4$ & $2.7-4.7$ \\
\hline NND-Dem & 17 & $9 / 8$ & $63.2 \pm 16.9$ & - & $182.2 \pm 151.5$ & $104.3-260.1$ & $3.1 \pm 2.4$ & $1.8-4.3$ \\
\hline \multicolumn{9}{|c|}{ Neurodegenerative and vascular dementia } \\
\hline$A D$ & 44 & $26 / 18$ & $68.5 \pm 10.9$ & - & $34.9 \pm 33.4$ & $24.7-45.8$ & $3.6 \pm 2.4$ & $2.8-4.3$ \\
\hline CJD & 83 & $53 / 30$ & $66.6 \pm 8.8$ & $273.4 \pm 276.9$ & $349.7 \pm 505.4$ & $239.4-460.1$ & $45.1 \pm 48.7$ & $34.5-55.7$ \\
\hline MM & 51 & $36 / 16$ & $66.8 \pm 9.6$ & $236.9 \pm 213.7$ & $384.5 \pm 492.7$ & $246.0-523.1$ & $59.8 \pm 54.4$ & $44.6-75.1$ \\
\hline MV & 11 & $4 / 7$ & $65.6 \pm 7.1$ & $316.3 \pm 20.1$ & $174.9 \pm 118.4$ & $95.3-254.4$ & $23.7 \pm 24.9$ & $6.9-40.4$ \\
\hline W & 18 & $11 / 7$ & $68.9 \pm 6.7$ & $369.5 \pm 417.3$ & $395.1 \pm 689.4$ & $52.3-737.9$ & $16.5 \pm 19.3$ & $6.9-26.2$ \\
\hline DLB/PDD & 35 & $11 / 24$ & $69.8 \pm 8.3$ & - & $46.8 \pm 37.1$ & $33.8-59.7$ & $2.3 \pm 1.4$ & $1.8-2.7$ \\
\hline FTD & 12 & $8 / 4$ & $69.5 \pm 7.2$ & - & $27.8 \pm 29.6$ & $7.9-47.8$ & $2.3 \pm 1.3$ & $1.4-3.1$ \\
\hline VAD & 22 & $15 / 5$ & $70.0 \pm 9.9$ & - & $56.35 \pm 51.7$ & $33.4-79.3$ & $3.2 \pm 2.8$ & $2.0-4.8$ \\
\hline
\end{tabular}

Number of cases studied, sex (number of female and male cases), age at onset (mean age with SD), and plasma Nfl and t-tau (mean concentrations with SD and $95 \% \mathrm{Cl}$ ) are indicated. Information on disease duration (onset to death, mean days, SD) is only available for the CJD group. HC, healthy controls; NND, neurological diseases without dementia; NND-Dem, neurological diseases with dementia; AD, Alzheimer's disease; CJD, Creutzfeldt-Jakob disease; MM/MV/VV, PRNP codon 129 methionine/valine polymorphism; DLB/PDD, dementia with Lewy bodies/Parkinson's disease dementia; FTD, fronto-temporal dementia; VaD, vascular dementia; $\mathrm{Nfl}$, neurofilament light; t-tau, total-tau. *Information on disease duration was available from 82 of 83 CJD cases 


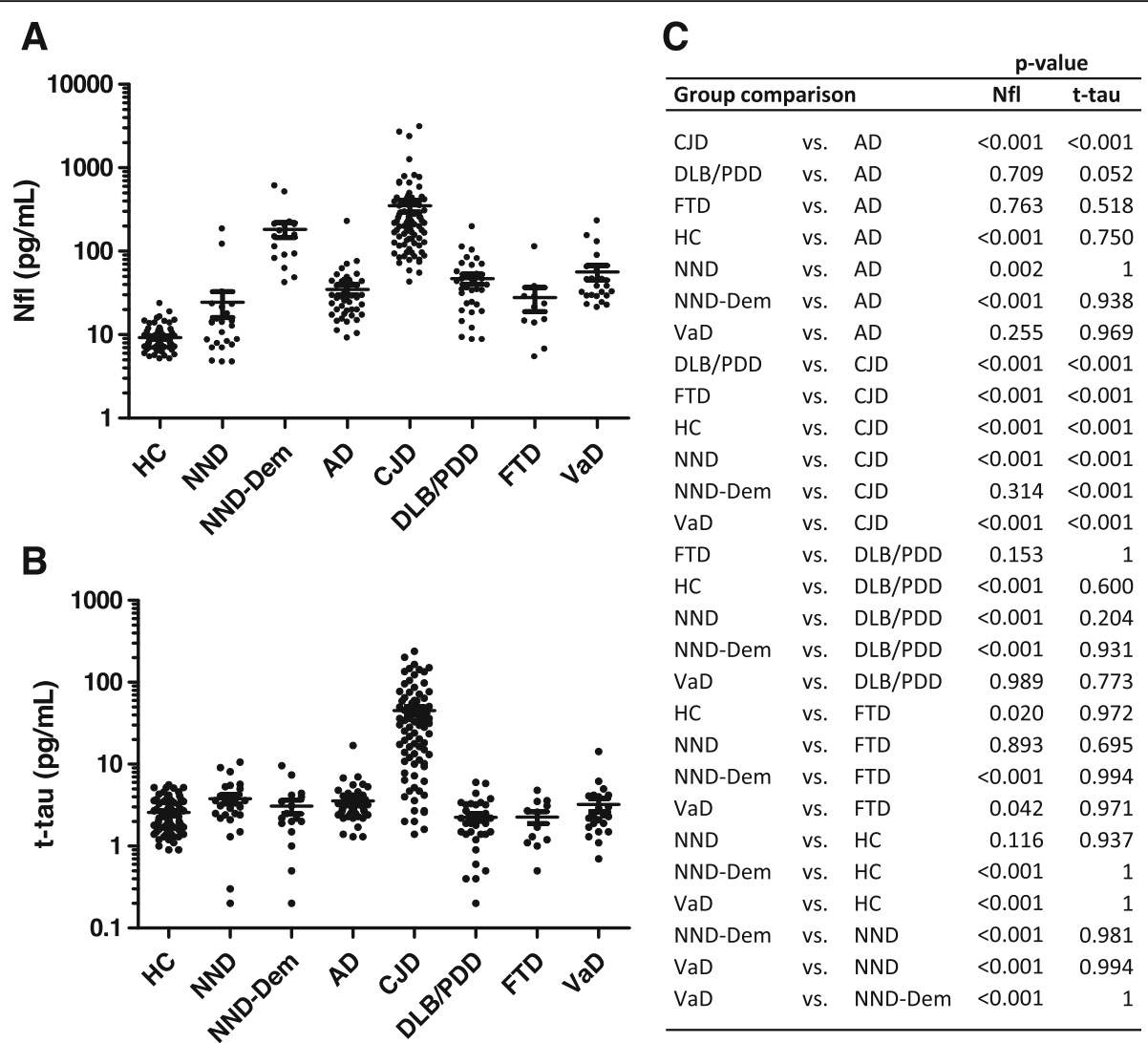

Fig. 1 Plasma Nfl and t-tau in the differential diagnosis of neurodegenerative dementia. Dot plot displaying a Nfl and $\mathbf{b}$ t-tau concentrations in the differential diagnosis of neurodegenerative dementia. c Statistical significance derived from a multi-comparative analysis corrected for covariates for Nfl and t-tau among the diagnostic groups (linear regression models were used, as explained in the "Statistical analysis" section). The Tukey-corrected $p$ values for each pair of diagnostic group comparison are indicated. HC, healthy controls; NND, neurological diseases without dementia; NND-Dem, neurological diseases with dementia; AD, Alzheimer's disease; CJD, Creutzfeldt-Jakob disease; DLB/PDD, dementia with Lewy bodies/Parkinson's disease dementia; FTD, fronto-temporal dementia; VaD, vascular dementia; Nfl, neurofilament light; t-tau, total-tau; f, female; $m$, male; SD, standard deviation

cases and lower accuracy discriminating from CJD cases (AUC $=0.67$ ). In contrast, $\mathrm{t}$-tau exclusively displayed a good discriminatory value in the differentiation of CJD from $\mathrm{HC}, \mathrm{NND}$, and NND-Dem (AUCs values ranging from 0.91 to 0.95). Significant differences in AUC values between $\mathrm{Nfl}$ and $\mathrm{t}$-tau for each comparison indicates high specificity for $\mathrm{t}$-tau in the discrimination of CJD cases from the other diagnostic groups, while $\mathrm{Nfl}$ resulted in a less specific test with a good diagnostic value in the discrimination of all conditions associated to dementia from $\mathrm{HC}$ and NND (Fig. 1c, Table 2). Overall, Nfl presented a slightly superior, but not significant, accuracy compared to t-tau in discriminating CJD from neurodegenerative dementias, with the exception of the $\mathrm{AD}$ vs. CJD comparison where $\mathrm{Nfl}$ significantly over performs t-tau (Table 2).

Plasma Nfl and t-tau displayed a positive and significant association in the NND-Dem (cc: 0.6957, $p=0.0019$ ) and CJD (cc: $0.3676, p<0.001$ ) groups (Additional file 1A and 1B), while no other significant correlations were detected in the rest of the diagnostic groups $(p>0.05)$. In CJD, a significant positive correlation was observed between plasma and CSF Nfl concentrations (cc: 0.5125, $p<0.001$ ) (Additional file $1 \mathrm{C}$ ) and between plasma and CSF t-tau concentrations (cc: $0.5425, p<0.001$ ) (Additional file 1C). Plasma Nfl was associated with CSF t-tau (cc: 0.3266, $p=$ 0.0109), but plasma $t$-tau was not associated with CSF Nfl. Plasma t-tau was associated with CSF 14-3-3 positivity $(p=0.0211)$. Plasma Nfl and $\mathrm{t}$-tau were associated neither with CSF A 422 nor with CSF t-PrP. Plasma Nfl, but not ttau, significantly correlated with plasma YKL-40 (cc: $0.4030 p=0.0081$ ) (Additional file 1C).

\section{Plasma Nfl and t-tau cutoff points for the differential diagnosis of CJD}

Cutoff points and associated sensitivity and specificity values for the discrimination of CJD from $\mathrm{HC}$ and nonCJD-Dem (NND-Dem, AD, FTD, DLB/PDD and VaD) were determined. Due to the significant differences on $\mathrm{Nfl}$ concentrations between AD, FTD, DLB/PDD, VaD 
Table 2 Diagnostic value of plasma $\mathrm{Nfl}$ and t-tau in the differential diagnosis of neurodegenerative dementias

\begin{tabular}{|c|c|c|c|c|c|}
\hline & \multicolumn{2}{|l|}{$\mathrm{Nfl}$} & \multicolumn{2}{|l|}{ t-tau } & \multirow[b]{2}{*}{$p$ value } \\
\hline & AUC & $95 \% \mathrm{Cl}$ & AUC & $95 \% \mathrm{Cl}$ & \\
\hline $\mathrm{HC}$ vs. $A D$ & 0.97 & $0.94-0.99$ & 0.67 & $0.57-0.77$ & $<0.001$ \\
\hline HC vs. CJD & 1 & 1 & 0.95 & $0.91-0.98$ & 0.003 \\
\hline HC vs. DLB/PDD & 0.95 & $0.91-0.99$ & 0.57 & $0.46-0.70$ & $<0.001$ \\
\hline HC vs. FTD & 0.81 & $0.61-1$ & 0.60 & $0.42-0.80$ & 0.1 \\
\hline HC vs. VaD & 0.99 & $0.99-1$ & 0.55 & $0.39-0.67$ & $<0.001$ \\
\hline NND vs. AD & 0.82 & $0.70-0.93$ & 0.52 & $0.37-0.67$ & $<0.001$ \\
\hline NND vs. CJD & 0.97 & $0.94-1$ & 0.91 & $0.86-0.96$ & 0.05 \\
\hline NND vs. DLB/PDD & 0.84 & $0.72-0.95$ & 0.71 & $0.57-0.85$ & 0.1 \\
\hline NND vs. FTD & 0.66 & $0.46-0.87$ & 0.69 & $0.52-0.87$ & 0.7 \\
\hline NND vs. VaD & 0.90 & $0.80-1$ & 0.62 & $0.45-0.78$ & 0.002 \\
\hline NND-Dem vs. AD & 0.95 & $0.90-1$ & 0.62 & $0.44-0.80$ & $<0.001$ \\
\hline NND-Dem vs. CJD & 0.67 & $0.53-0.80$ & 0.93 & $0.89-0.98$ & $<0.001$ \\
\hline NND-Dem vs. DLB/PDD & 0.91 & $0.83-0.99$ & 0.56 & $0.42-0.77$ & 0.001 \\
\hline NND-Dem vs. FTD & 0.97 & $0.90-1$ & 0.58 & $0.36-0.79$ & $<0.001$ \\
\hline NND-Dem vs. VaD & 0.88 & 0.780 .99 & 0.51 & $0.32-0.69$ & 0.002 \\
\hline AD vs. CJD & 0.98 & $0.96-1$ & 0.91 & $0.87-0.96$ & 0.01 \\
\hline AD vs. DLB/PDD & 0.62 & $0.49-0.75$ & 0.72 & $0.61-0.84$ & 0.3 \\
\hline AD vs. FTD & 0.66 & $0.46-0.85$ & 0.70 & $0.51-0.88$ & 0.7 \\
\hline AD vs. VaD & 0.69 & $0.56-0.82$ & 0.63 & $0.48-0.79$ & 0.6 \\
\hline CJD vs. DLB/PDD & 0.96 & $0.93-0.99$ & 0.96 & $0.92-0.99$ & 0.7 \\
\hline CJD vs. FTD & 0.98 & $0.95-1$ & 0.96 & $0.92-0.99$ & 0.2 \\
\hline CJD vs. VaD & 0.94 & $0.88-0.99$ & 0.93 & $0.88-0.98$ & 0.8 \\
\hline DLB/PDD vs. FTD & 0.72 & $0.54-0.90$ & 0.51 & $0.30-0.70$ & 0.08 \\
\hline DLB/PDD vs. VaD & 0.47 & $0.37-0.68$ & 0.60 & $0.45-0.75$ & 0.3 \\
\hline FTD vs. VaD & 0.82 & $0.65-0.99$ & 0.63 & $0.40-0.82$ & 0.1 \\
\hline
\end{tabular}

AUC derived from ROC curves, with $95 \% \mathrm{Cl}$ in the comparative analysis of $\mathrm{HC}$, NND, and NND-Dem vs. neurodegenerative dementia and between the different neurodegenerative dementia groups are indicated. Statistical differences ( $p$ values) between AUC values for Nfl and t-tau in the comparisons between pairs of diagnostic groups calculated as explained in the "Statistical analysis" section. AUC, area under the curve; ROC, receiver operating characteristic; $95 \% \mathrm{Cl}, 95 \%$ confidence interval; $\mathrm{HC}$, healthy controls; NND, neurological diseases without dementia; NND-Dem, neurological diseases with dementia; AD, Alzheimer's disease; CJD, Creutzfeldt-Jakob disease; DLB/PDD, dementia with Lewy bodies/Parkinson's disease dementia; FTD, fronto-temporal dementia; $\mathrm{VaD}$, vascular dementia; Nfl, neurofilament light; t-tau, total-tau

and NND-Dem, an additional group including only neurodegenerative dementias (AD, FTD, DLB/PDD and $\mathrm{VaD}$ ) named non-CJD neurodeg-Dem was defined and included in the analysis. At $33 \mathrm{pg} / \mathrm{mL}$ Nfl cutoff, CJD was discriminated from $\mathrm{HC}$ with $100 \%$ sensitivity and specificity. At $70 \mathrm{pg} / \mathrm{mL}$ Nfl cutoff, CJD was discriminated from non-CJD-Dem with 79\% sensitivity and 96\% specificity and from non-CJD neurodeg-Dem (excluding NND-Dem) with $88 \%$ sensitivity and $96 \%$ specificity (Table 3). At $6.0 \mathrm{pg} / \mathrm{mL}$ t-tau cutoff, CJD was discriminated from $\mathrm{HC}$ with $84 \%$ sensitivity and $100 \%$ specificity.
At $6.1 \mathrm{pg} / \mathrm{mL}$ t-tau cutoff, CJD discriminated from nonCJD-Dem and non-CJD neurodeg-Dem with 95\% sensitivity and $84 \%$ (Table 3 ).

\section{Plasma Nfl and t-tau in the differential diagnosis of CJD from $A D$ subtypes}

Rapid progressive forms of $\mathrm{AD}$ have been widely described, being one of the main differential diagnosis of CJD due to their partial overlap on clinical presentation and biomarker profile [33]. Thus, we examined whether different $\mathrm{Nfl}$ and $\mathrm{t}$-tau profiles were observed between slow progressive (spAD) and rapid progressive (rpAD) AD cases. Plasma Nfl displayed significantly higher concentrations in $\mathrm{rpAD}(52.1 \pm 49.6 \mathrm{pg} / \mathrm{mL})$ than in $\mathrm{spAD}$ $(25.5 \pm 11.7 \mathrm{pg} / \mathrm{mL})$ (Fig. 2a), with an associated AUC of $0.79(95 \% \mathrm{CI}=0.64-0.93)$. In contrast, no differences in t-tau concentrations were observed between rpAD $(3.3 \pm 1.7 \mathrm{pg} / \mathrm{mL})$ and $\operatorname{spAD}(3.3 \pm 1.1 \mathrm{pg} / \mathrm{mL})$ (Fig. 2b), with an associated AUC of $0.57(95 \% \mathrm{CI}=0.37-0.77)$. The higher $\mathrm{Nfl}$ concentrations in rapid progressive forms of $\mathrm{AD}$ were in agreement with a significant negative correlation between Nfl and MMSE score (Fig. 2c), an association that was not observed for t-tau (Fig. 2d). To investigate this further and to exclude that the plasma Nfl differences between spAD and rpAD are solely associated with lower MMSE scores in the rpAD group, we performed an additional linear regression model. When age, sex, and MMSE scores were included, higher Nfl concentrations still showed a significant association with $\operatorname{rpAD}(p=0.028)$. Nfl had a higher accuracy than $\mathrm{t}$-tau discriminating CJD from $\operatorname{spAD}(\mathrm{Nfl}$ AUC $=$ 0.99 vs. $t$-tau $\mathrm{AUC}=0.95$ ) and CJD from $\operatorname{rpAD}(\mathrm{Nfl}$ $\mathrm{AUC}=0.95$ vs. $\mathrm{t}$-tau AUC $=0.92$ ). However, differences between AUCs were only significant for the spAD vs. CJD comparison (Fig. 2e).

\section{Influence of codon 129 PRNP genotype and CJD subtype}

To further investigate the role of different CJD subtypes in plasma $\mathrm{Nfl}$ and $\mathrm{t}$-tau concentrations, CJD cases were stratified according to codon usage (Methionine $(\mathrm{M})$ or Valine (V)) at position 129 of the PRNP gene. It determines the clinico-pathological features of the disease [34] and is a well-known modifier of Nfl and t-tau accuracy in biological fluids in prion diseases $[7,14,15$, 35]. In a multi-comparative analysis corrected for covariates, no significantly different $\mathrm{Nfl}$ concentrations were detected between MM $(384.5 \pm 492.7 \mathrm{pg} / \mathrm{mL}), \quad$ MV $(174.9 \pm 118.4 \mathrm{pg} / \mathrm{mL})$, and $\mathrm{VV}(395.1 \pm 689.4 \mathrm{pg} / \mathrm{mL})$ cases (Fig. 3a). In contrast, t-tau concentrations were significantly higher in $\mathrm{MM}(59.4 \pm 54.4 \mathrm{pg} / \mathrm{mL})$ compared to $\mathrm{MV}(23.6 \pm 24.9 \mathrm{pg} / \mathrm{mL})$ and to $\mathrm{VV}(16.5 \pm 19.3 \mathrm{pg} /$ $\mathrm{mL}$ ) cases (Fig. 3b). Given the influence of codon 129 PRNP genotype on $\mathrm{Nfl}$ and $\mathrm{t}$-tau profiles in CJD cases, we sought to determine the diagnostic performance of 
Table 3 Diagnostic accuracy of plasma Nfl and t-tau in the discrimination of CJD

\begin{tabular}{|c|c|c|c|c|c|c|}
\hline \multirow[b]{2}{*}{ CJD vs. } & \multicolumn{3}{|l|}{ Plasma Nfl } & \multicolumn{3}{|l|}{ Plasma t-tau } \\
\hline & Cutoff & Sensitivity (\%) & Specificity (\%) & Cutoff & Sensitivity (\%) & Specificity (\%) \\
\hline $\mathrm{HC}$ & $>33 \mathrm{pg} / \mathrm{mL}$ & 100 & 100 & $>6.0 \mathrm{pg} / \mathrm{mL}$ & 84 & 100 \\
\hline Non-CJD-Dem & $>70 \mathrm{pg} / \mathrm{mL}$ & 79 & 96 & $>6.1 \mathrm{pg} / \mathrm{mL}$ & 95 & 84 \\
\hline Non-CJD-neurodeg-Dem & $>70 \mathrm{pg} / \mathrm{mL}$ & 88 & 96 & $>6.1 \mathrm{pg} / \mathrm{mL}$ & 95 & 84 \\
\hline
\end{tabular}

Sensitivity (in \%), specificity (in \%), and associated cutoff points (in $\mathrm{pg} / \mathrm{mL}$ ) for plasma Nfl and t-tau in the discrimination of CJD from HC, non-CJD-Dem, and non-CJD neurodeg-Dem
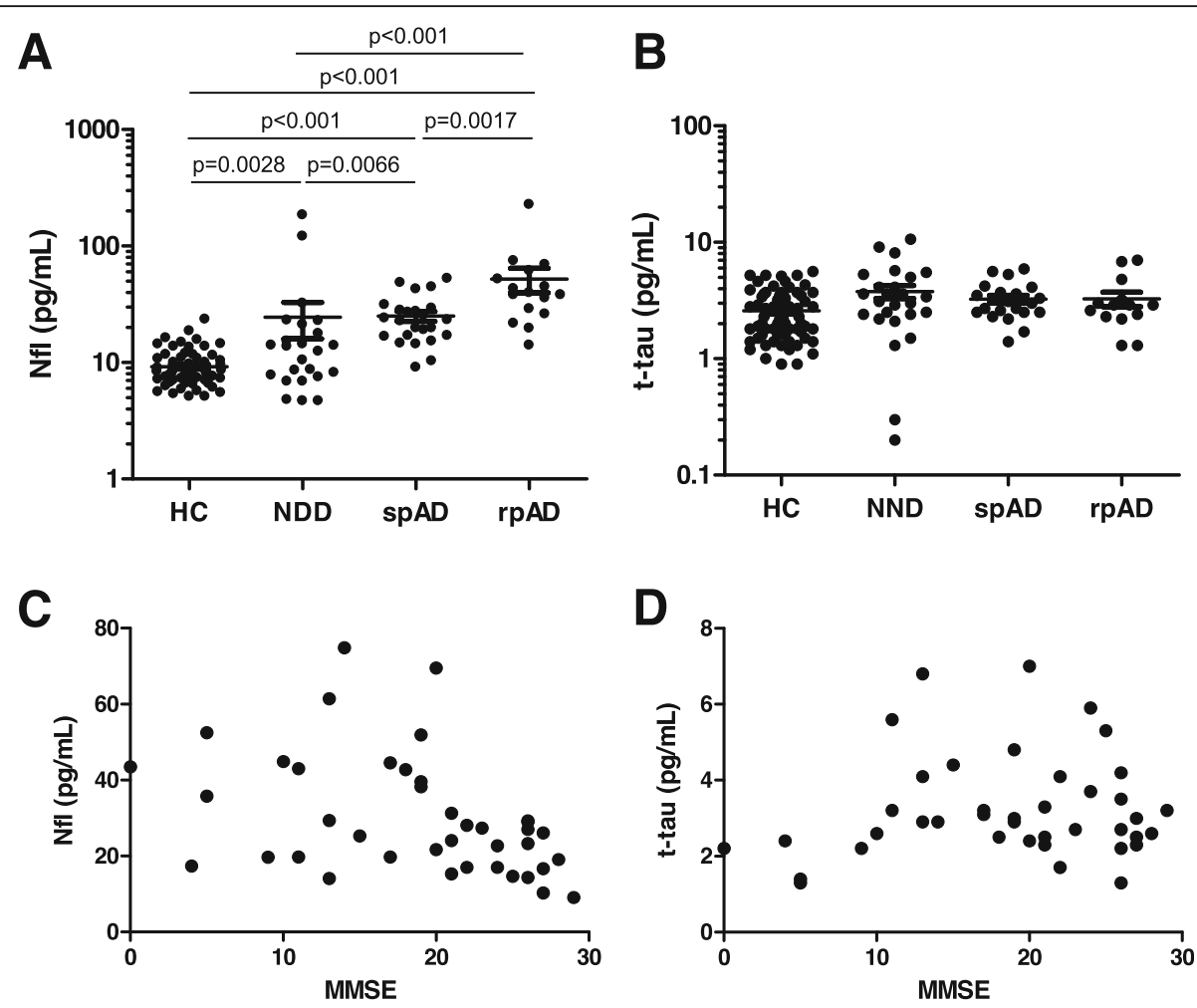

cc $(95 \% \mathrm{Cl}):-0.4045(-0.6359-(-0.1063))$
p value: 0.0096

cc $(95 \% \mathrm{Cl}): 0.1060(-0.2126-0.4043)$ $p$ value: 0.5149

E

$\operatorname{AUC}(95 \% \mathrm{Cl})$

\begin{tabular}{|c|c|c|c|}
\hline & & \multirow[b]{2}{*}{$p$ value } \\
\hline & $\mathrm{Nfl}$ & t-tau & \\
\hline spAD vs. CJD & $0.99(0.99-1)$ & $0.92(0.87-0.97)$ & 0.002 \\
\hline rpAD vs. CJD & $0.95(0.89-1)$ & $0.92(0.87-0.97)$ & 0.500 \\
\hline
\end{tabular}

Fig. 2 Plasma $\mathrm{Nfl}$ and t-tau in different AD subtypes and discrimination from CJD. Dot plot displaying a $\mathrm{Nfl}$ and $\mathbf{b}$ t-tau concentrations in $\mathrm{HC}(n=$ $70), \operatorname{NND}(n=26), \operatorname{spAD}(n=24)$, and rpAD $(n=16)$. Statistical significance derived from a comparative analysis corrected for covariates is indicated. Correlation analysis between plasma Nfl (c) and t-tau (d) concentrations with MMSE in AD cases. Correlation coefficients with $95 \% \mathrm{Cl}$ and associated $p$ values derived from Spearmen test analysis are indicated. e AUC derived from ROC curves, with $95 \% \mathrm{Cl}$ in the comparative analysis of spAD and rpAD from CJD cases. $p$ values derived from the comparative analysis of AUCs are indicated (corresponding statistical test is explained in Statistical analysis). AD, Alzheimer's disease; spAD, slow progressive AD; rpAD, rapid progressive AD; Nfl, neurofilament light; t-tau, total-tau; AUC, area under the curve; ROC, receiver operating characteristic; 95\% Cl, 95\% confidence interval 

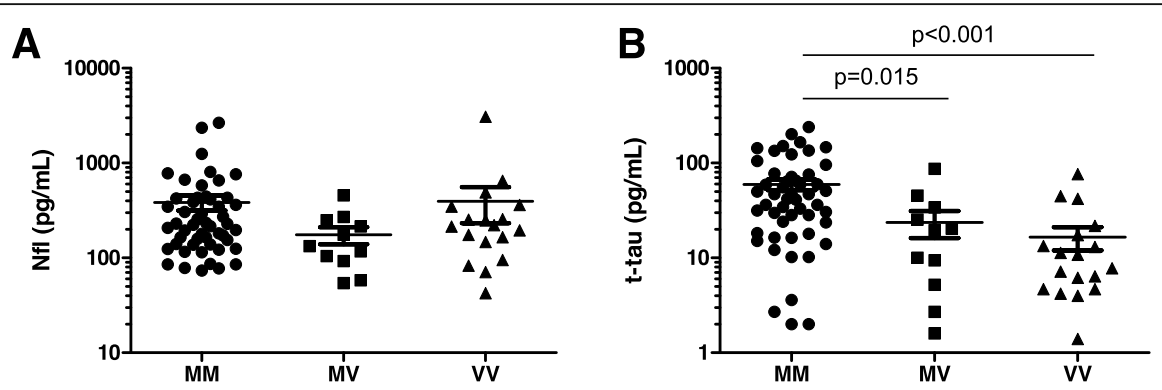

C

D
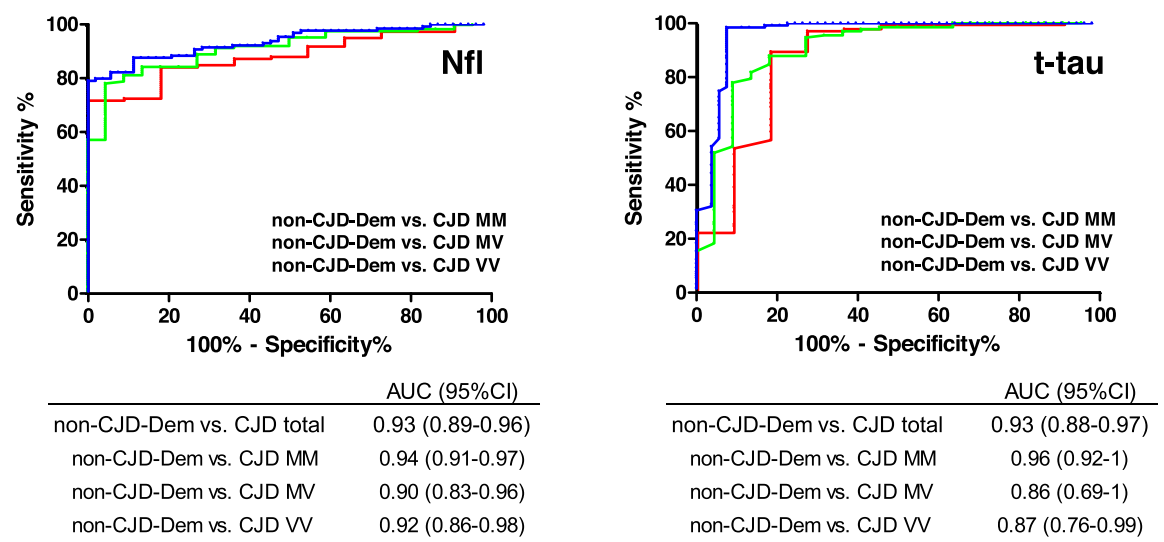

$\mathbf{E}$

$\mathbf{F}$
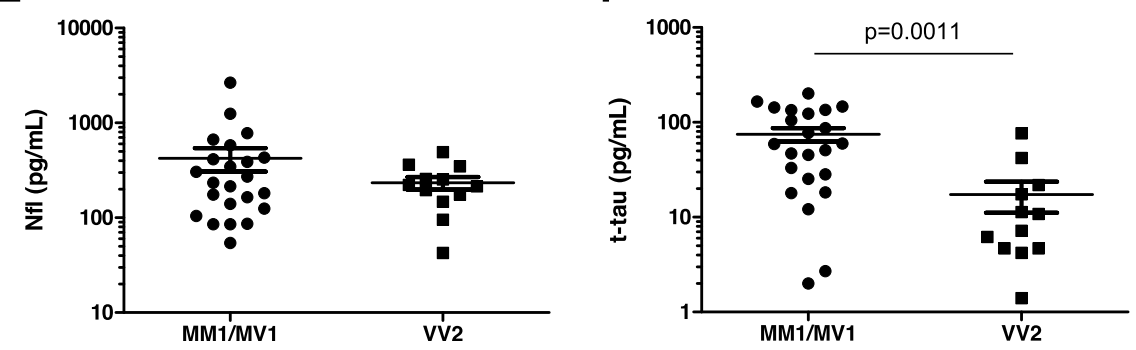

Fig. 3 Influence of codon 129 PRNP genotype and subtype in plasma Nfl and t-tau in CJD. a Nfl and $\mathbf{b}$ t-tau concentrations in CJD stratified by prion protein gene (PRNP) codon 129 genotype (MM, $n=51 ; M V, n=11 ; \mathrm{W}, n=18$ ). Statistical significance derived from a multi-comparative analysis corrected for covariates for Nfl and t-tau is indicated (linear regression models were used, as explained in the "Statistical analysis" section). Dot plots with mean (line) values are shown. ROC curves for Nfl (c) and t-tau (d) in the comparative analysis of non-CJD-Dem vs. CJD cases stratified by codon 129 PRNP genotype. AUC derived from ROC curves, with 95\% Cl in the comparative analysis of non-CJD-Dem vs. total CJD cases and CJD cases stratified by codon 129 PRNP genotype are shown. e Nfl and $\mathbf{f}$ t-tau concentrations in CJD MM1/MV1 ( $n=23)$ and W2 ( $n=$ 12) subtypes. Statistical significance derived from a comparative analysis corrected for covariates is indicated. Dot plots with mean (line) values are shown. Non-CJD-Dem, non-neurodegenerative dementia; Nfl, neurofilament light; t-tau, total-tau

both biomarkers in the discrimination of CJD from neurodegenerative dementias from a non-prion etiology. To this purpose, different types of dementias (NND-Dem, AD, DLB/PDD, FTD, and VaD) were grouped under the non-CJD dementia label (nonCJD-Dem), and AUC values calculated for CJD cases stratified by codon 129 genotype. In total CJD cases, equal AUCs were obtained for $\mathrm{Nfl}$ and $\mathrm{t}$-tau in the discrimination of non-CJD-Dem $($ AUC $=0.93$ ) (Fig. 3c, d). Stratification by PRNP codon 129 genotype had a stronger influence in $\mathrm{t}$-tau (AUCs ranging from 0.86 to 0.96), than in $\mathrm{Nfl}$ (AUCs ranging from 0.90 to 0.94).

Regarding CJD subtype, data were available for the two most prevalent subtypes. While no differences were detected in $\mathrm{Nfl}$ concentrations between MM1/MV1 $(423.1 \pm 561.9 \mathrm{pg} / \mathrm{mL})$ and VV2 $(233.6 \pm 122.9 \mathrm{pg} / \mathrm{mL})$ cases (Fig. 3e), $\mathrm{t}$-tau was significantly increased in MM1/ MV1 $(75.0 \pm 58.2 \mathrm{pg} / \mathrm{mL})$ compared to VV2 $(17.4 \pm 21.7$ $\mathrm{pg} / \mathrm{mL}$ ) cases (Fig. 3f). 


\section{Relation with disease stage and prognostic value of plasma Nfl and t-tau in CJD}

To evaluate a potential association between $\mathrm{Nfl}$ and $\mathrm{t}$ tau levels at the time of blood collection and the timeliness of the disease in CJD patients, samples were stratified in early (1st Ter), middle (2nd Ter) and late stages (3rd Ter). However, neither Nfl nor t-tau concentrations were significantly different between disease stages (Fig. 4a, b). Next we stratified cases according whether patients presented early symptoms or akinetic mutism at the time of sampling (as explained in Study Population). Cases in akinetic mutism showed significantly higher Nfl and $t$-tau levels than those at early stage of the disease (Fig. 4c, d).

To ascertain whether plasma Nfl and t-tau were associated to disease duration, CJD cases were stratified in those displaying short and long course (lower and higher than mean disease duration, respectively). Nfl concentrations were not significantly different between CJD cases displaying short and long survival times. In contrast, higher $\mathrm{t}$-tau concentrations were detected in CJD cases with short survival time $(p=0.0088)$. Association between disease duration and biomarker data was explored with Spearman correlation coefficients. Due to the difficulty to precisely define disease duration in prion diseases, in our study, we considered two starting points: from disease onset to death and from blood uptake to death. Significant associations were observed in the case of $\mathrm{t}$-tau ( $\mathrm{cc}=-0.3236$ and $\mathrm{cc}=-0.3166$, when disease duration was considered from disease onset and blood uptake respectively), but not in the case of Nfl (Fig. 4df). Given these results, we built Cox $\mathrm{PH}$ models with ttau and $\mathrm{Nfl}$ as predictors to observe the effect over disease duration. As expected, only t-tau behaved as a significant predictor, although with very modest hazard ratios (HR), which is not surprising considering the unit used to measure the biomarker (pg/mL) (Additional file 2). Non-linear relationships between disease duration and plasma t-tau were also explored (Additional file 2), but the best models displayed only moderate fitting, with concordance indices of 0.6 (i.e., $60 \%$ of concordant prediction-value pairs) [36].

\section{Comparative analysis of plasma and CSF accuracy in CJD diagnosis and prognosis}

In order to comparatively evaluate the accuracy of plasma and CSF Nfl and t-tau, both biomarkers were measured in available paired CSF cases in CJD and neurodegenerative dementia (non-CJD-Dem) cases. Plasma and CSF Nfl showed a similar accuracy in discriminating non-CJD-Dem from CJD (plasma $\mathrm{AUC}=0.91$ and CSF $\mathrm{AUC}=0.90)$ (Fig. 5a). In contrast, CSF t-tau (AUC = 0.97) displayed superior accuracy than plasma t-tau $(\mathrm{AUC}=0.93)$ in the same comparative analysis (Fig. 5b).
Association between biomarkers and disease duration was explored with Spearman correlation coefficient to compare the potential prognostic value of CSF vs. plasma markers in the group of available paired cases. While both CSF t-tau and Nfl levels were strongly inversely associated with disease duration, particularly when this was measured from blood uptake (cc $=-$ 0.5093 and $\mathrm{cc}=-0.3983$ for CSF t-tau and CSF Nfl, respectively), only plasma t-tau showed association with disease duration $(\mathrm{cc}=-0.2803)$. As also observed in the previous section, plasma Nfl totally lacked of prognostic value (Fig. 5c).

\section{Discussion}

Plasma Nfl and t-tau in the differential diagnosis of CJD

The differential diagnosis of neurodegenerative dementia may be challenging due to overlapping clinical features among different conditions. Here, we explored the diagnostic accuracy of plasma Nfl and t-tau in the differential diagnosis of CJD, identified the influence of demographic and genetic factors on biomarker levels and determined the diagnostic value of both biomarkers in the differential diagnostic context. Our data validate previous reports describing elevated blood $\mathrm{Nfl}$ and t-tau in CJD compared to $\mathrm{HC}[14,15]$ as well as to nondemented controls [11].

Additionally, we observed that, despite the overall accuracy of both biomarkers discriminating CJD from non-CJD dementias is similar $(\mathrm{AUC}=0.93)$, t-tau concentrations are dependent on the genetic characteristics of the CJD population (codon 129 genotype). Importantly, the accuracy of both biomarkers is highly dependent to the diagnostic group to which CJD is compared. In this regard, while Nfl displays a high sensitivity discriminating CJD from non-demented controls, test specificity is hampered by the presence of high concentrations in non-CJD dementias. In contrast, t-tau was somewhat less sensitive than $\mathrm{Nfl}$ discriminating CJD form non-demented controls, but offers higher test specificity for CJD. This, together with the observation that $\mathrm{Nfl}$ concentrations are significantly higher in NND-Dem compared with non-CJD neurodegenerative dementias, discloses the complementarity of both biomarkers in the differential diagnosis of CJD. Thus, t-tau performs better than $\mathrm{Nfl}$ in discriminating CJD from NND-Dem, whereas Nfl becomes more useful in discriminating early CID with non-specific symptoms from NND. For the differentiation of CJD from neurodegenerative dementias, slightly superior but not significantly higher accuracies were achieved by $\mathrm{Nfl}$ compared to $\mathrm{t}$-tau, with the exception of the CJD vs. AD comparison for which Nfl significantly outperforms t-tau. In this regard, we also explored the value of plasma $\mathrm{Nfl}$ and $\mathrm{t}$-tau in $\mathrm{rpAD}$, which represents a recurrent alternative diagnosis in 

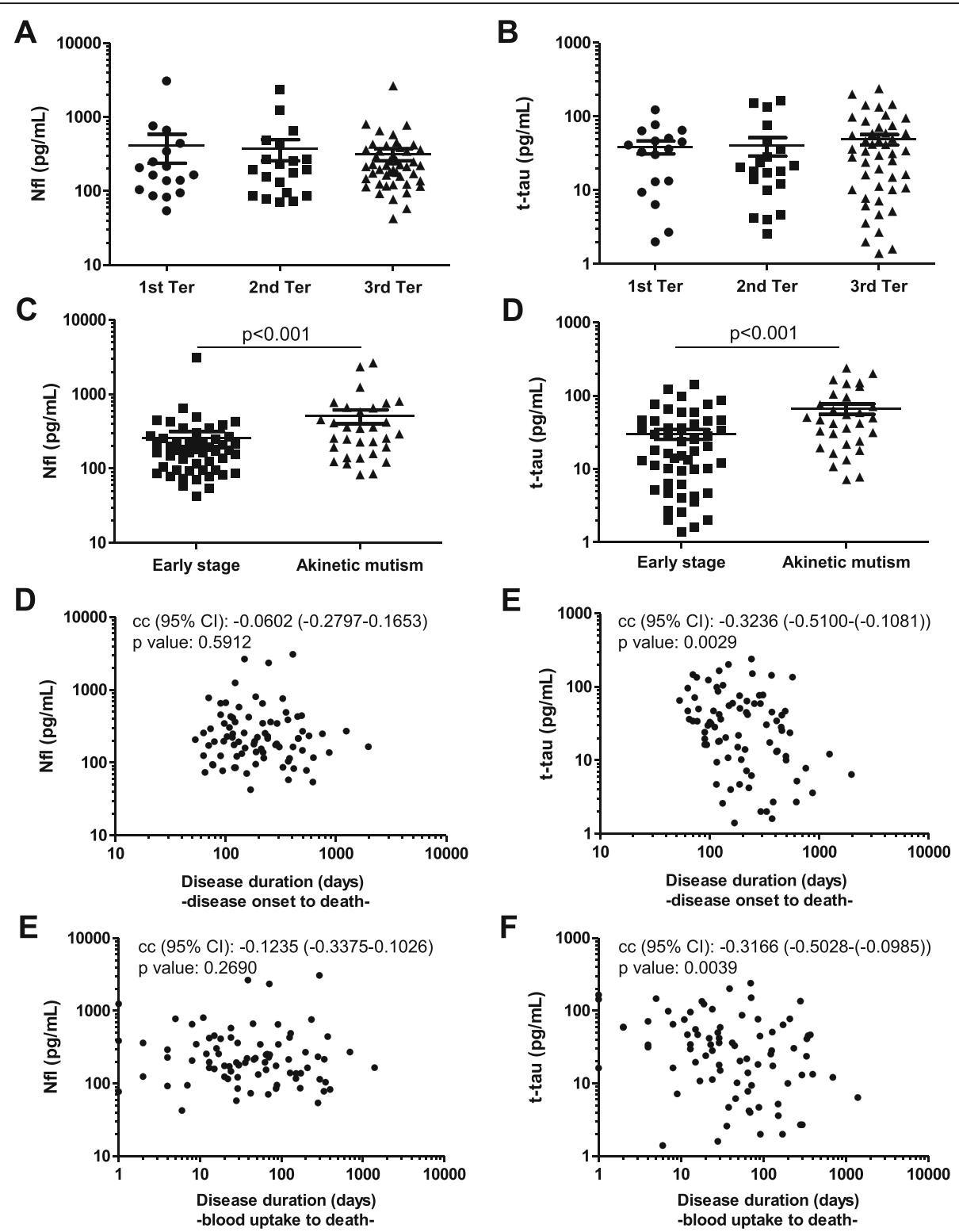

Fig. 4 Relation with disease stage and prognostic value of plasma Nfl and t-tau in CJD. Plasma Nfl (a) and t-tau (b) concentrations in CJD cases stratified in three categories according to whether blood was collected in the first stage/tertial (1st Ter, $n=17)$ (time of blood uptake to disease onset/total duration of the disease $<0.33$ ), second stage/tertial (2nd Ter, $n=20)(0.33-0.66)$, or third stage/tertial $(3 r d$ Ter, $n=46)(>0.66)$ of the disease. Plasma $\mathrm{Nfl}(\mathbf{c})$ and t-tau (d) in CJD cases classified as early stage $(n=51)$ and akinetic mutism $(n=31)$. Resultant significant corrected $p$ values are displayed. Nfl, neurofilament light; t-tau, total-tau. $\mathbf{d}-\mathbf{f}$ Association between disease duration (considered from disease onset and from blood uptake) and plasma $\mathrm{Nfl}$ and t-tau, measured with Spearman correlation coefficients (cc) and corresponding $p$ values

cases referred to prion disease surveillance centers due to its clinical overlap with CJD [34]. The stratification of $\mathrm{AD}$ according to rate of cognitive decline reveals that, in spite of the higher $\mathrm{Nfl}$ concentrations in rpAD compared to spAD, Nfl performs better than t-tau discriminating rpAD from CJD (AUC 0.95 vs. 0.92). Interestingly, elevated $\mathrm{Nfl}$ has been reported in other non-CJD rapid progressive neurological syndromes including $\mathrm{AD}$ and those presenting vascular, neoplastic and inflammatory alterations [14].
We report distinctive optimal cutoff points considering that the diagnostic accuracy may vary with clinically suspected etiology of differential diagnoses. An optimal cutoff for t-tau $(6.1 \mathrm{pg} / \mathrm{mL})$ displays same accuracy discriminating CJD from the rest of dementia syndromes regardless their etiology whereas $\mathrm{Nfl}$ sensitivity resulting from the optimal cutoff of $70 \mathrm{pg} / \mathrm{mL}$ decreases when the NND-Dem group is included, as a consequence of its above mentioned high $\mathrm{Nfl}$ concentrations. However, these cutoffs cannot be applied in a clinical context until 
A
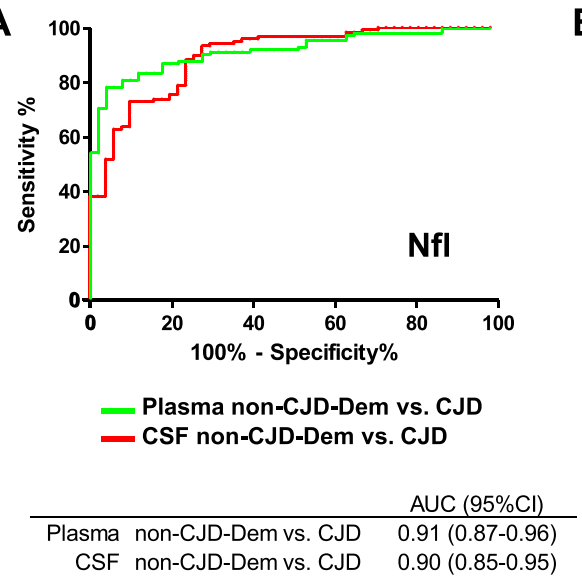

CSF non-CJD-Dem vs. CJD $0.90(0.85-0.95)$

B

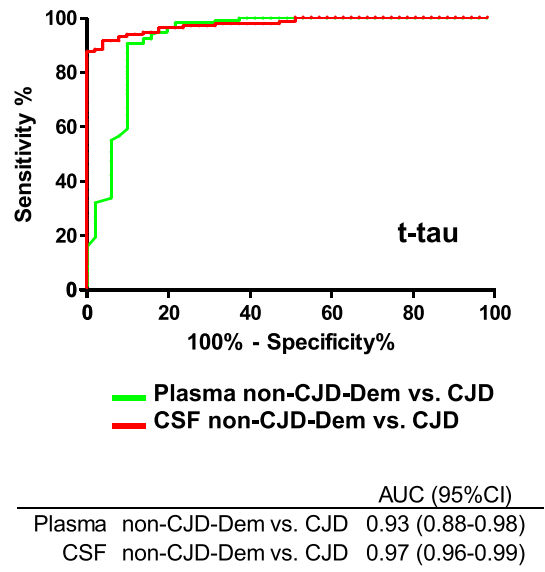

C

\begin{tabular}{ccccc} 
& \multicolumn{2}{c}{ Disease duration from onset } & \multicolumn{2}{c}{ Disease duration from blood uptake } \\
\cline { 2 - 5 } Predictor & $\mathrm{cc}$ & $\mathrm{p}$ value & $\mathrm{cc}$ & $\mathrm{p}$ value \\
\hline Plasma t-tau & -0.2837 & 0.0295 & -0.2803 & 0.0316 \\
CSF t-tau & -0.2928 & 0.0244 & -0.5093 & $<0.0001$ \\
Plasma Nfl & 0.0308 & 0.8169 & -0.0424 & 0.7501 \\
CSF Nfl & -0.3045 & 0.0316 & -0.3983 & 0.0042
\end{tabular}

Fig. 5 Comparative analysis of plasma and CSF biomarkers accuracy in CJD diagnosis and disease duration. a, b ROC curves with associated AUC values in the comparative analysis of CJD $(n=51)$ vs. non-CJD-Dem $(n=118)$ groups obtained with t-tau and Nfl in CSF and plasma. c Association of plasma and CSF t-tau and $\mathrm{Nfl}$ with disease duration measured with Spearman correlation coefficients (cc) and corresponding $p$ values

they have been validated in independent cohorts. Different cutoff points have been described in the bibliography, e.g., $2.2 \mathrm{pg} / \mathrm{mL}$ for $\mathrm{t}$-Tau and $44.7 \mathrm{pg} / \mathrm{mL}$ for $\mathrm{NfL}$ [11], but these were not comparable to the present ones as they were obtained in serum and included prion diseases from different etiologies and a mixture of nondemented and demented controls.

In agreement with previous observations, we validated the role of codon 129 genotype in t-tau concentrations in CJD [14, 15], with MM cases presenting higher t-tau concentrations than those harboring MV and VV. Importantly, knowledge about PRNP codon 129 genotype and the type of suspected differential diagnosis (either a non-neurodegenerative neurological disease with dementia syndrome or a neurodegenerative dementia) may be useful in determining which biomarker may display higher clinical value in the differential diagnosis of CJD. Similarly, our analyses put forward the possibility to determine distinct cutoff points for each codon 129 genotype, which will probably result in improved classification performance in the case of $\mathrm{t}$-tau. Regarding autopsy-confirmed confirmed CJD cases, $\mathrm{t}$-tau, but not $\mathrm{Nfl}$, concentrations were significantly higher in CJD MM1/MV1 compared to VV2 cases in agreement with previous data [37], suggesting that despite positive correlations in plasma, $\mathrm{Nfl}$, and $\mathrm{t}$-tau reflect different (or only partially overlapping) pathological features in brain tissue. In this regard, while $\mathrm{Nfl}$ is mainly expressed in myelinated subcortical axons [38], t-tau displays a widely neuronal expression in the brain [39], and different strain-dependent regional neuronal vulnerability has been reported in CJD [34, 40]. Additionally, differences can be attributed to differential entrance and stability of both proteins in the bloodstream.

Because blood collection is performed at different stages of the disease, we analyzed the influence of the time of sampling in the biomarker levels in CJD. Cases in akinetic mutism at the time of sampling had higher plasma Nfl and $\mathrm{t}$-tau levels than those at early stages of the disease. These data are in line with previous studies demonstrating the relationship between plasma $\mathrm{t}$-tau and Nfl with disease progression in CJD [41]. In contrast, no differences were found between time points during disease course (tertials), potentially due to heterogeneous application of life-extending treatment or earlier blood uptakes in patients with fast disease progression.

An important observation of this study is that while plasma and CSF Nfl display similar accuracies in the discrimination of CJD from non-CJD dementias, CSF t-tau outperforms plasma $\mathrm{t}$-tau, as well as plasma and CSF Nfl. This is in agreement with previous reports showing highest accuracies for CSF t-tau comparing CJD vs. non-CJD cases among the four biomarker combinations [11, 37]. 
The observation that $\mathrm{Nfl}$ and $\mathrm{t}$-tau exclusively correlate in NND-Dem and CJD groups, both displaying extremely high Nfl values, may help to shed some light on the different clearance pathway of both proteins from plasma. We hypothesize that when moderate neuronal damage occurs, different clearance or turnover mechanisms lead to an absence of correlation between both biomarkers. Instead, when massive neuronal damage occurs, this effect is masked by massive accumulation of both proteins in plasma leading to a positive correlation between both proteins. Whether blood concentrations do really mirror alterations in the brain tissue needs to be carefully addressed. Some biomarkers may be expressed in other tissues or their concentrations in blood may not reflect alterations in brain due to different interchange mechanism between fluids, different modifications and forms. In this sense, our correlation analyses in paired plasma-CSF cases indicate that the plasma levels of both proteins reflect cerebral alterations.

\section{Plasma Nfl and t-tau in AD and VD}

We also validated previous observations in $\mathrm{AD}$, reporting moderately increase or no significance differences on plasma t-tau levels between $\mathrm{AD}$ and cognitive normal controls $[42,43]$. However, while plasma t-tau lacks accuracy as a diagnostic AD marker, it is associated with an increased risk of cognitive decline in MCI [44] and AD [45] being proposed as a potential non-specific predictive biomarker of dementia [45]. Interestingly, in our AD group, plasma $\mathrm{Nfl}$, but not $\mathrm{t}$-tau, showed a significant association with MMSE. This is in agreement with data reporting increasing $\mathrm{Nfl}$ concentrations with increasing symptoms severity [46] and its correlation with CSF AD markers, hippocampal volume loss, and FDGPET hypometabolism [47, 48]. Our analyses in $\mathrm{VaD}$ cases showed high levels of plasma Nfl (only lower than those of CJD and NND-Dem), which is in line with previous studies demonstrating the association of plasma $\mathrm{Nfl}$ and the risk of $\mathrm{VaD}$ [49]. By contrast, plasma t-tau was not altered in $\mathrm{VaD}$. Indeed, it seems that this biomarker in case of vascular disease is only a good marker in acute cerebrovascular events [50].

\section{Prognostic value of plasma Nfl and t-tau in CJD}

Although disease duration in CJD is strongly determined by individual features such as age at onset, sex and PRNP codon 129 genotype [51, 52], the potential prognostic capacity of several fluid biomarkers is under investigation, with t-tau highlighting as one of the more promising candidates [52, 53]. In the present work, we observed a strong association between disease duration and plasma t-tau in CJD, in line with previous reports $[37,53]$. It was shown that the combinatory use of information on CSF t-Tau and PRNP codon 129 genotype has a higher prognostic value than genotype alone [52]. Our PH model included codon 129 genotype as a controlling factor and suggests that plasma t-Tau may have potential to function in a similar way. By contrast, we did not find a significant association between survival and plasma Nfl in our study cohort. This association has been previously reported but seemed to be dependent on the CJD subtype and, upon stratification of cases, plasma Nfl was only associated with survival in a group of slowly progressive prion diseases [37]. Discrepancies between our findings and previously published studies can be related to the lack of CJD stratification, which we chose not to perform since CJD subtype information is not known at the time of diagnosis. Another reason is the different definition of survival in CJD. Whereas other authors considered relevant survival time until akinetic mutism stage when life-extending treatments are applied, we strictly considered survival time until death. This issue involves ethics considerations and needs to be clarified to reach a consensus definition of survival in these prognostic analyses.

\section{Study strengths and limitations}

The main limitations of our study are the absence of serial samples, impeding assessment of longitudinal changes in biomarker levels, and the absence of an external validation cohort, which implies bias in the reported diagnostic accuracies. We suggest that future validation studies should aim to include longitudinal samples but this might be complicated by short survival time in CJD. To resolve this problem, the intervals between blood uptakes have to be carefully thought out. Differences might be detectable even over short time periods of 2 or 4 weeks. In our study, blood and CSF sampling were performed in close temporal association. In some cases however, blood-uptake was performed up to a maximum of 15 days later than lumbar puncture. In the context of a rapidly progressive diseases, even this rather short period of time may possibly lead to an overestimation of the diagnostic accuracy of plasma markers in comparison to CSF markers. Although samples from CJD patients were initially collected in the framework of a prospective study, case selection was done retrospectively, based on availability of sufficient information and biomaterial. Naturally, this comes along with potential biases such as the possibility that the study cohort might not exactly reflect the phenotypical spectrum of CJD at diagnosis in the population. On the other hand, the majority of CJD subtypes and PRNP Codon 129 Genotypes were MM/MV1 and MM, respectively, similar to what is known from previous observations [6].

The strengths of our study include the quantification of the biomarkers in the most common neurodegenerative dementias relevant in the CJD differential diagnostic 
context, especially the rapidly progressing forms of $\mathrm{AD}$. In addition, the availability of clinically well-characterized samples allowed investigating the influence of the time of blood collection in the biomarker concentrations, which is uncommon in this type of studies.

\section{Conclusions}

In total, our data validate previous observations and show that plasma $\mathrm{Nfl}$ and $\mathrm{t}$-tau are clinically relevant biomarkers for the diagnosis of CJD with the potential to become the first blood-based diagnostic biomarkers to be implemented in the clinical settings. Our data shows that CJD subtype and certain diagnoses in the control group are associated with different diagnostic accuracies of plasma $\mathrm{Nfl}$ and $\mathrm{t}-\mathrm{Tau}$, underlining the importance of a thorough consideration of differential diagnoses and suggesting potential benefit from a combined use of both biomarkers. Plasma t-tau may also contribute to predict disease duration in CJD, with implications in counseling and interpretation of clinical trials, whereas plasma $\mathrm{Nfl}$ is associated with disease stage and progression in $\mathrm{AD}$.

\begin{abstract}
Abbreviations
A 342 : Amyloid $\beta$; AD: Alzheimer's disease; AUC: Areas under the curve; CJD: Creutzfeldt-Jakob disease; CNS: Central nervous system; CSF: Cerebrospinal fluid; DLB: Dementia with Lewy bodies; FTD: Frontotemporal dementia; HC: Healthy controls; MMSE: Mini Mental Status Examination; Nfl: Neurofilament light; NND: Non-neurodegenerative neurological disease without dementia controls; NND-Dem: Nonneurodegenerative neurological disease with dementia controls; PDD: Parkinson's disease dementia; PH: Proportional hazards; ptau: Phosphorylated-tau; rpAD: Rapid progressive AD; RT-QulC: Real-time quacking induced conversion assay; ROC: Receiver operating characteristic; spAD: Slow progressive AD; t-tau: Total-tau; VaD: Vascular dementia
\end{abstract}

\section{Supplementary Information}

The online version contains supplementary material available at https://doi. org/10.1186/s13195-021-00815-6.

Additional file 1. Plasma Nfl and t-tau correlations in the study population. A. Correlation analysis between plasma $\mathrm{Nfl}$ and t-tau concentrations in the study population stratified by disease group. Correlation coefficients with $95 \% \mathrm{Cl}$ and associated $p$ values derived from Spearman test analysis are indicated for each comparison. Statistically significant differences are shown in bold. B. Scatter plot with plasma Nfl and t-tau concentrations in CJD. HC: healthy controls, NND: neurological diseases without dementia, NND-Dem: neurological diseases with dementia, AD: Alzheimer's disease, CJD: Creutzfeldt-Jakob disease, DLB/PDD: dementia with Lewy bodies/Parkinson's disease dementia, FTD: fronto-temporal dementia and VaD: vascular dementia, cc: correlation coefficient, 95\% Cl: 95\% confidence interval. C. Correlation analysis in CJD cases between plasma Nfl and plasma t-tau concentrations with CSF Nfl, CSF t-tau, CSF Aß42, plasma YKL-40, plasma t-PrP concentrations. Correlation coefficients with $95 \% \mathrm{Cl}$ and associated $p$ values derived from Spearman test analysis are indicated for each comparison. Association between plasma NFI and t-tau with CSF 14-3-3 positivity was analyzed using the Mann-Whitney $U$ test. Number of paired cases used in the analysis is indicated. Statistically significant differences are shown in bold. D. Scatter plots with plasma Nfl vs. CSF Nfl and E. plasma t-tau vs. CSF t-tau concentrations in CJD. CC: correlation coefficient, 95\% Cl: 95\% confidence interval, n: number. Nfl: neurofilament light, t-tau: total-tau, A 342 : amyloid beta 42 .
Additional file $\mathbf{2}$ Relationship between plasma t-tau and disease duration in CJD. A. Resultant hazard ratios (HR) and associated $p$-values from Cox $\mathrm{PH}$ models, in which disease duration was the response variable and the biomarker (in $\mathrm{pg} / \mathrm{mL}$ ) was the predictor, performed as explained in Statistical analysis. B. When allowing for non-linear relationships (using the multivariable fractional polynomial method), the best fit considering disease duration from disease onset was obtained with the logarithmic transformation of the biomarker data. The Cox PH model rendered a concordance of 0.6098 ( $\mathrm{SE}=0.0301)$.C. When disease duration was measured from blood uptake, the best fit model was obtained without the logarithmic transformation, and the resultant $\mathrm{Cox} \mathrm{PH}$ model offered a concordance of 0.6080 (SE $=0.0359)$.

\section{Acknowledgements}

We thank CERCA Programme of Generalitat de Catalunya for institutional support.

\section{Authors' contributions}

$\mathrm{IZ}, \mathrm{AV}-\mathrm{P}$, and $\mathrm{FL}$ designed the study. AV-P, $H Z, K B$, and FL performed experiments. IZ, AV-P, PH, IF, HZ, KB, and FL analyzed data and interpreted the results. IZ, PH, MS, DV, and JR contributed to the sample collection and characterization. FL, AV-P, and PH wrote the manuscript draft. All authors critically revised the manuscript and approved its content before submission.

\section{Funding}

This study was funded by the Instituto Carlos III (grant PI19/00144) to FL and by the Robert Koch Institute through funds from the Federal Ministry of Health (grant No, 1369-341) to IZ. This project was also funded at $65 \%$ by the Fondo Europeo de Desarrollo Regional (FEDER) through the Interreg V-A España-Francia-Andorra (POCTEFA 2014-2020) programme. AVP is supported by the Beatriu de Pinós programme (2018-BP-00129) from the Ministry of Business and Knowledge of the Government of Catalonia, cofunded by the EU Horizon 2020 programme under an MSCA grant agreement (801370). HZ is a Wallenberg Scholar supported by grants from the Swedish Research Council (\#2018-02532), the European Research Council (\#681712), Swedish State Support for Clinical Research (\#ALFGBG-720931), the Alzheimer Drug Discovery Foundation (ADDF), USA (\#201809-2016862), and the UK Dementia Research Institute at UCL. KB is supported by the Swedish Research Council (\#2017-00915), the Alzheimer Drug Discovery Foundation (ADDF), USA (\#RDAPB-201809-2016615), the Swedish Alzheimer Foundation (\#AF-742881), Hjärnfonden, Sweden (\#FO2017-0243), the Swedish state under the agreement between the Swedish government and the County Councils, the ALFagreement (\#ALFGBG-715986), and European Union Joint Program for Neurodegenerative Disorders (JPND2019-466-236).

\section{Availability of data and materials}

The datasets used and analyzed during the current study are available from the corresponding author on reasonable request.

\section{Declarations}

Ethics approval and consent to participate

The study was conducted according to the revised Declaration of Helsinki and Good Clinical Practice guidelines and was approved by all local Ethics committees (reference numbers 11/11/93, 5/09/08, 9/06/08, 19/11/09 University Medical School, Göttingen, Germany). All study participants or their legal guardians provided written informed consent.

\section{Consent for publication}

Not applicable.

\section{Competing interests}

$\mathrm{HZ}$ has served at scientific advisory boards for Denali, Roche Diagnostics, Wave, Samumed, Siemens Healthineers, Pinteon Therapeutics, and CogRx, has given lectures in symposia sponsored by Fujirebio, Alzecure, and Biogen, and is a co-founder of Brain Biomarker Solutions in Gothenburg AB (BBS), which is a part of the GU Ventures Incubator Program. KB has served as a consultant, at advisory boards, or at data monitoring committees for Abcam, Axon, Biogen, Julius Clinical, Lilly, MagQu, Novartis, Roche Diagnostics, and 
Siemens Healthineers, and is a co-founder of Brain Biomarker Solutions in Gothenburg AB (BBS), which is a part of the GU Ventures Incubator Program.

\section{Author details \\ 'Department of Neurology, National Reference Center for TSE Surveillance, University Medical Center, Robert-Koch Street 40, Göttingen, Germany. ${ }^{2}$ German Center for Neurodegenerative Diseases (DZNE), Göttingen, Spain. ${ }^{4}$ Bellvitge Biomedical Research Institute (IDIBELL), L'Hospitalet de Llobregat, Spain. ${ }^{5}$ Department of Pathology and Experimental Therapeutics, University of Barcelona, L'Hospitalet de Llobregat, Spain. ${ }^{6}$ Department of Transfusion Medicine, University Medical School, Göttingen, Germany. ${ }^{7}$ Department of Psychiatry and Neurochemistry, Institute of Neuroscience Institute of Neurology, London, UK. ${ }^{10}$ UK Dementia Research Institute, London, UK. \\ Received: 29 September 2020 Accepted: 23 March 2021 Published online: 21 April 2021} Germany. ${ }^{3}$ Center for Networked Biomedical Research in Neurodegenerative Diseases (CIBERNED), L'Hospitalet de Llobregat, Feixa Llarga s/n, Barcelona, and Physiology, The Sahlgrenska Academy at the University of Gothenburg, Mölndal, Sweden. ${ }^{8} \mathrm{Clinical}$ Neurochemistry Laboratory, Sahlgrenska University Hospital, Mölndal, Sweden. 'Department of Neurodegenerative Disease, UCL

\section{References}

1. Koikkalainen J, Rhodius-Meester H, Tolonen A, Barkhof F, Tijms B, Lemstra AW, Tong T, Guerrero R, Schuh A, Ledig C, Rueckert D, Soininen H, Remes AM, Waldemar G, Hasselbalch S, Mecocci P, van der Flier W, Lötjönen J. Differential diagnosis of neurodegenerative diseases using structural MRI data. Neurolmage Clin. 2016;11:435-49. https://doi.org/10.1016/j.nicl.2016.02.019.

2. Llorens F, Schmitz M, Ferrer I, Zerr I. CSF biomarkers in neurodegenerative and vascular dementias. Prog Neurobiol. 2016;138-140:36-53.

3. Lewczuk P, Riederer P, O'Bryant SE, Verbeek MM, Dubois B, Visser PJ, et al. Cerebrospinal fluid and blood biomarkers for neurodegenerative dementias: an update of the Consensus of the Task Force on Biological Markers in Psychiatry of the World Federation of Societies of Biological Psychiatry. World J Biol Psychiatry. 2017;2975:1-85.

4. McKhann GM, Knopman DS, Chertkow H, Hyman BT, Jack CR, Kawas CH, et al. The diagnosis of dementia due to Alzheimer's disease: recommendations from the National Institute on Aging-Alzheimer's Association workgroups on diagnostic guidelines for Alzheimer's disease. Alzheimers Dement. 2011;7(3): 263-9. https://doi.org/10.1016/j.jalz.2011.03.005.

5. Hermann P, Laux M, Glatzel M, Matschke J, Knipper T, Goebel S, Treig J, Schulz-Schaeffer W, Cramm M, Schmitz M, Zerr I. Validation and utilization of amended diagnostic criteria in Creutzfeldt-Jakob disease surveillance. Neurology. 2018;91(4):e331-8. https://doi.org/10.1212/WNL. 0000000000005860 .

6. Zerr I, Kallenberg K, Summers DM, Romero C, Taratuto A, Heinemann U, Breithaupt M, Varges D, Meissner B, Ladogana A, Schuur M, Haik S, Collins SJ, Jansen GH, Stokin GB, Pimentel J, Hewer E, Collie D, Smith P, Roberts H, Brandel JP, van Duijn C, Pocchiari M, Begue C, Cras P, Will RG, Sanchez-Juan P. Updated clinical diagnostic criteria for sporadic Creutzfeldt-Jakob disease. Brain. 2009;132(10):2659-68. https://doi.org/10.1093/brain/awp191.

7. Zerr I, Schmitz M, Karch A, Villar-Piqué A, Kanata E, Golanska E, et al. Cerebrospinal fluid neurofilament light levels in neurodegenerative dementia: evaluation of diagnostic accuracy in the differential diagnosis of prion diseases. Alzheimers Dement. 2018:4:751-63.

8. Skillback T, Farahmand B, Bartlett JW, Rosen C, Mattsson N, Nagga K, Kilander L, Religa D, Wimo A, Winblad B, Rosengren L, Schott JM, Blennow K, Eriksdotter M, Zetterberg $\mathrm{H}$. CSF neurofilament light differs in neurodegenerative diseases and predicts severity and survival. Neurology. 2014;83(21):1945-53. https://doi.org/10.1212/WNL.0000000000001015.

9. Scherling CS, Hall T, Berisha F, Klepac K, Karydas A, Coppola G, Kramer JH, Rabinovici G, Ahlijanian M, Miller BL, Seeley W, Grinberg LT, Rosen H, Meredith J Jr, Boxer AL. Cerebrospinal fluid neurofilament concentration reflects disease severity in frontotemporal degeneration. Ann Neurol. 2014; 75(1):116-26. https://doi.org/10.1002/ana.24052.

10. Andreasson $\mathrm{U}$, Blennow $\mathrm{K}$, Zetterberg $\mathrm{H}$. Update on ultrasensitive technologies to facilitate research on blood biomarkers for central nervous system disorders. Alzheimers Dement (Amst). 2016;3(1):98-102. https://doi. org/10.1016/j.dadm.2016.05.005.
11. Steinacker P, Blennow K, Halbgebauer S, Shi S, Ruf V, Oeckl P, Giese A, Kuhle J, Slivarichova D, Zetterberg H, Otto M. Neurofilaments in blood and CSF for diagnosis and prediction of onset in Creutzfeldt-Jakob disease. Sci Rep. 2016;6(1):38737. https://doi.org/10.1038/srep38737.

12. Rohrer JD, Woollacott IOC, Dick KM, Brotherhood E, Gordon E, Fellows A, Toombs J, Druyeh R, Cardoso MJ, Ourselin S, Nicholas JM, Norgren N, Mead S, Andreasson U, Blennow K, Schott JM, Fox NC, Warren JD, Zetterberg H. Serum neurofilament light chain protein is a measure of disease intensity in frontotemporal dementia. Neurology. 2016;87(13):1329-36. https://doi.org/1 0.1212 WNL.0000000000003154.

13. Chen Z, Mengel D, Keshavan A, Rissman RA, Billinton A, Perkinton M, Percival-Alwyn J, Schultz A, Properzi M, Johnson K, Selkoe DJ, Sperling RA, Patel P, Zetterberg H, Galasko D, Schott JM, Walsh DM. Learnings about the complexity of extracellular tau aid development of a blood-based screen for Alzheimer's disease. Alzheimers Dement. 2019;15(3):487-96. https://doi.org/1 0.1016/j.jalz.2018.09.010.

14. Kovacs GG, Andreasson U, Liman V, Regelsberger G, Lutz Ml, Danics K, Keller E, Zetterberg H, Blennow K. Plasma and cerebrospinal fluid tau and neurofilament concentrations in rapidly progressive neurological syndromes: a neuropathology-based cohort. Eur J Neurol. 2017;24(11):132677. https://doi.org/10.1111/ene.13389.

15. Thompson AGB, Luk C, Heslegrave AJ, Zetterberg H, Mead SH, Collinge J, Jackson GS. Neurofilament light chain and tau concentrations are markedly increased in the serum of patients with sporadic Creutzfeldt-Jakob disease, and tau correlates with rate of disease progression. J Neurol Neurosurg Psychiatry. 2018;89(9):955-61. https://doi.org/10.1136/jnnp-2017-317793.

16. Foiani MS, Woollacott IOC, Heller C, Bocchetta M, Heslegrave A, Dick KM, Russell LL, Marshall CR, Mead S, Schott JM, Fox NC, Warren JD, Zetterberg H, Rohrer JD. Plasma tau is increased in frontotemporal dementia. J Neurol Neurosurg Psychiatry. 2018;89(8):804-7. https://doi.org/10.1136/jnnp-2017-31 7260 .

17. Villemagne $V L$, Burnham $S$, Bourgeat $P$, Brown B, Ellis KA, Salvado O, Szoeke C, Macaulay SL, Martins R, Maruff P, Ames D, Rowe CC, Masters CL, Australian Imaging Biomarkers and Lifestyle (AIBL) Research Group. Amyloid beta deposition, neurodegeneration, and cognitive decline in sporadic Alzheimer's disease: a prospective cohort study. Lancet Neurol. 2013;12(4): 357-67. https://doi.org/10.1016/S1474-4422(13)70044-9.

18. McKeith IG, Boeve BF, Dickson DW, Halliday G, Taylor J-P, Weintraub D, et al. Diagnosis and management of dementia with Lewy bodies: fourth consensus report of the DLB Consortium. Neurology. 2017;89(1):88-100. https://doi.org/10.1212/WNL.0000000000004058.

19. Emre M, Aarsland D, Brown R, Burn DJ, Duyckaerts C, Mizuno Y, Broe GA, Cummings J, Dickson DW, Gauthier S, Goldman J, Goetz C, Korczyn A, Lees A, Levy R, Litvan I, McKeith I, Olanow W, Poewe W, Quinn N, Sampaio C, Tolosa E, Dubois B. Clinical diagnostic criteria for dementia associated with Parkinson's disease. Mov Disord. 2007;22(12):1689-707. https://doi.org/10.1 002/mds.21507.

20. Armstrong MJ, Litvan I, Lang AE, Bak TH, Bhatia KP, Borroni B, Boxer AL, Dickson DW, Grossman M, Hallett M, Josephs KA, Kertesz A, Lee SE, Miller BL, Reich SG, Riley DE, Tolosa E, Troster Al, Vidailhet M, Weiner WJ. Criteria for the diagnosis of corticobasal degeneration. Neurology. 2013;80(5):496503. https://doi.org/10.1212/WNL.0b013e31827fofd1.

21. Höglinger GU, Respondek G, Stamelou M, Kurz C, Josephs KA, Lang AE, Mollenhauer B, Müller U, Nilsson C, Whitwell JL, Arzberger T, Englund E, Gelpi E, Giese A, Irwin DJ, Meissner WG, Pantelyat A, Rajput A, van Swieten JC, Troakes C, Antonini A, Bhatia KP, Bordelon Y, Compta Y, Corvol JC, Colosimo C, Dickson DW, Dodel R, Ferguson L, Grossman M, Kassubek J, Krismer F, Levin J, Lorenzl S, Morris HR, Nestor P, Oertel WH, Poewe W, Rabinovici G, Rowe JB, Schellenberg GD, Seppi K, van Eimeren T, Wenning GK, Boxer AL, Golbe LI, Litvan I, for the Movement Disorder Societyendorsed PSP Study Group. Clinical diagnosis of progressive supranuclear palsy: the movement disorder society criteria. Mov Disord. 2017;32(6):85364. https://doi.org/10.1002/mds.26987.

22. Gilman S, Wenning GK, Low PA, Brooks DJ, Mathias CJ, Trojanowski JQ, Wood NW, Colosimo C, Durr A, Fowler CJ, Kaufmann H, Klockgether T, Lees A, Poewe W, Quinn N, Revesz T, Robertson D, Sandroni P, Seppi K, Vidailhet M. Second consensus statement on the diagnosis of multiple system atrophy. Neurology. 2008;71(9):670-6. https://doi.org/10.1212/01.wnl. 0000324625.00404 .15

23. Rascovsky K, Hodges JR, Knopman D, Mendez MF, Kramer JH, Neuhaus J, van Swieten JC, Seelaar H, Dopper EGP, Onyike CU, Hillis AE, Josephs KA, 
Boeve BF, Kertesz A, Seeley WW, Rankin KP, Johnson JK, Gorno-Tempini ML, Rosen H, Prioleau-Latham CE, Lee A, Kipps CM, Lillo P, Piguet O, Rohrer JD, Rossor MN, Warren JD, Fox NC, Galasko D, Salmon DP, Black SE, Mesulam M, Weintraub S, Dickerson BC, Diehl-Schmid J, Pasquier F, Deramecourt V, Lebert F, Pijnenburg Y, Chow TW, Manes F, Grafman J, Cappa SF, Freedman M, Grossman M, Miller BL. Sensitivity of revised diagnostic criteria for the behavioural variant of frontotemporal dementia. Brain. 2011;134(9):2456-77. https://doi.org/10.1093/brain/awr179.

24. Román GC, Tatemichi TK, Erkinjuntti T, Cummings JL, Masdeu JC, Garcia JH, et al. Vascular dementia: diagnostic criteria for research studies. Report of the NINDS-AIREN International Workshop. Neurology. 1993;43(2):250-60. https://doi.org/10.1212/WNL.43.2.250.

25. Villar-Piqué A, Schmitz M, Hermann P, Goebel S, Bunck T, Varges D, Ferrer I, Riggert J, Llorens F, Zerr I. Plasma YKL-40 in the spectrum of neurodegenerative dementia. J Neuroinflammation. 2019;16(1):145. https:// doi.org/10.1186/s12974-019-1531-3.

26. Llorens F, Villar-Piqué A, Schmitz M, Diaz-Lucena D, Wohnlage M, Hermann $P$, et al. Plasma total prion protein as a potential biomarker for neurodegenerative dementia: diagnostic accuracy in the spectrum of prion diseases. Neuropathol Appl Neurobiol. 2020;46(3):240-54. https://doi.org/1 0.1111/nan.12573.

27. Zerr I, Bodemer M, Gefeller O, Otto M, Poser S, Wiltfang J, Windl O, Kretzschmar HA, Weber T. Detection of 14-3-3 protein in the cerebrospinal fluid supports the diagnosis of Creutzfeldt-Jakob disease. Ann Neurol. 1998; 43(1):32-40. https://doi.org/10.1002/ana.410430109.

28. Bretz F, Hothorn T, Westfall P. Multiple comparisons using R. Multiple comparisons using R. Boca Raton: CRC Press; 2010.

29. Robin X, Turck N, Hainard A, Tiberti N, Lisacek F, Sanchez JC, Müller M, PROC: an open-source package for R and S+ to analyze and compare ROC curves. BMC Bioinformatics. 2011;12(1):77. https://doi.org/10.1186/1471-21 05-12-77.

30. Therneau TM, Grambsch PM. Modeling survival data: extending the Cox model. New York: Springer; 2000. https://doi.org/10.1007/978-1-4757-3294-8.

31. Royston P, Altman DG. Regression using fractional polynomials of continuous covariates: parsimonious parametric modelling. Appl Stat. 1994; 43(3):429. https://doi.org/10.2307/2986270.

32. Breheny $P$, Burchett $W$. Visualization of regression models using visreg. $R J$ J. 2017;9(2):56-71. https://doi.org/10.32614/RJ-2017-046.

33. Zerr I, Hermann P. Diagnostic challenges in rapidly progressive dementia. Expert Rev Neurother. 2018;18(10):761-72. https://doi.org/10.1080/147371 75.2018.1519397.

34. Gambetti P, Kong Q, Zou W, Parchi P, Chen SG. Sporadic and familial CJD: classification and characterisation. Br Med Bull. 2003;66(1):213-39. https:// doi.org/10.1093/bmb/66.1.213.

35. Karch A, Hermann P, Ponto C, Schmitz M, Arora A, Zafar S, Llorens F, MüllerHeine A, Zerr I. Cerebrospinal fluid tau levels are a marker for molecular subtype in sporadic Creutzfeldt-Jakob disease. Neurobiol Aging. 2015;36(5): 1964-8. https://doi.org/10.1016/j.neurobiolaging.2015.01.021.

36. Therneau T, Atkinson E. Concordance. In: Package "survival"; 2020. Cran.rproject.org. https://cran.r-project.org/web/packages/survival/survival.pdf.

37. Rumeileh SA, Baiardi S, Ladogana A, Zenesini C, Stella AB, Poleggi A, et al. Comparison between plasma and cerebrospinal fluid biomarkers for the early diagnosis and association with survival in prion disease. J Neurol Neurosurg Psychiatry. 2020;91(11):1181-8. https://doi.org/10.1136/jnnp-202 0-323826.

38. Schlaepfer WW, Lynch RG. Immunofluorescence studies of neurofilaments in the rat and human peripheral and central nervous system. J Cell Biol. 1977; 74(1):241-50. https://doi.org/10.1083/jcb.74.1.241.

39. Majounie E, Cross W, Newsway V, Dillman A, Vandrovcova J, Morris CM, et al. Variation in tau isoform expression in different brain regions and disease states. Neurobiol Aging. 2013;34:1922.e7-1922.e12.

40. Parchi P, Castellani R, Capellari S, Ghetti B, Young K, Chen SG, Farlow M, Dickson DW, Sima AAF, Trojanowski JQ, Petersen RB, Gambetti P. Molecular basis of phenotypic variability in sporadic Creutzfeldt-Jakob disease. Ann Neurol. 1996;39(6):767-78. https://doi.org/10.1002/ana.410390613.

41. Thompson A, Anastasiadis P, Druyeh R, Whitworth I, Nayak A, Nihat A, et al. Evaluation of plasma tau and neurofilament light chain biomarkers in a 12year clinical cohort of human prion diseases. 2020. Preprint at: https://www. medrxiv.org/content/early/2020/07/29/2020.07.27.20157594.

42. Zetterberg $\mathrm{H}$, Blennow K. From cerebrospinal fluid to blood: the third wave of fluid biomarkers for Alzheimer's disease. J Alzheimers Dis. 2018;64:271-9.
43. Mattsson $\mathrm{N}$, Zetterberg $\mathrm{H}$, Janelidze $\mathrm{S}$, Insel PS, Andreasson U, Stomrud E, Palmqvist S, Baker D, Tan Hehir CA, Jeromin A, Hanlon D, Song L, Shaw LM, Trojanowski JQ, Weiner MW, Hansson O, Blennow K, ADNI Investigators. Plasma tau in Alzheimer disease. Neurology. 2016;87(17):1827-35. https:// doi.org/10.1212/WNL.0000000000003246.

44. Mielke MM, Hagen CE, Wennberg AMV, Airey DC, Savica R, Knopman DS, Machulda MM, Roberts RO, Jack CR Jr, Petersen RC, Dage JL. Association of plasma total tau level with cognitive decline and risk of mild cognitive impairment or dementia in the Mayo Clinic study on aging. JAMA Neurol. 2017;74(9):1073-80. https://doi.org/10.1001/jamaneurol.2017.1359.

45. Pase MP, Beiser AS, Himali JJ, Satizabal CL, Aparicio HJ, Decarli C, et al, Assessment of plasma total tau level as a predictive biomarker for dementia and related endophenotypes. JAMA Neurol. 2019;76(5):598-606. https://doi. org/10.1001/jamaneurol.2018.4666.

46. Preische O, Schultz SA, Apel A, Kuhle J, Kaeser SA, Barro C, et al. Serum neurofilament dynamics predicts neurodegeneration and clinical progression in presymptomatic Alzheimer's disease. Nat Med. 2019;25(2): 277-83. https://doi.org/10.1038/s41591-018-0304-3.

47. Mattsson N, Cullen NC, Andreasson U, Zetterberg H, Blennow K. Association between longitudinal plasma neurofilament light and neurodegeneration in patients with Alzheimer disease. JAMA Neurol. 2019;76(7):791-9. https://doi. org/10.1001/jamaneurol.2019.0765

48. Mielke MM, Syrjanen JA, Blennow K, Zetterberg H, Vemuri P, Skoog I, Machulda MM, Kremers WK, Knopman DS, Jack C Jr, Petersen RC, Kern S. Plasma and CSF neurofilament light: relation to longitudinal neuroimaging and cognitive measures. Neurology. 2019;93(3):e252-60. https://doi.org/1 0.1212 WNL. 0000000000007767.

49. de Wolf F, Ghanbari M, Licher S, McRae-McKee K, Gras L, Weverling GJ, Wermeling P, Sedaghat S, Ikram MK, Waziry R, Koudstaal W, Klap J, Kostense S, Hofman A, Anderson R, Goudsmit J, Ikram MA. Plasma tau, neurofilament light chain and amyloid- $\beta$ levels and risk of dementia; a population-based cohort study. Brain. 2020;143(4):1220-32. https://doi.org/10.1093/brain/awaa054.

50. Onatsu J, Vanninen R, Jäkäläp, Mustonen P, Pulkki K, Korhonen M, et al. Tau, S100B and NSE as blood biomarkers in acute cerebrovascular events. Vivo. 2020;34(5):2577-86. https://doi.org/10.21873/invivo.12075.

51. Pocchiari M, Puopolo M, Croes EA, Budka H, Gelpi E, Collins S, et al. Predictors of survival in sporadic Creutzfeldt-Jakob disease and other human transmissible spongiform encephalopathies. Brain. 2004;127(10): 2348-59. https://doi.org/10.1093/brain/awh249.

52. Llorens F, Rübsamen N, Hermann P, Schmitz M, Villar-Piqué A, Goebel S, et al. A prognostic model for overall survival in sporadic Creutzfeldt-Jakob disease. Alzheimers Dement. 2016;12(5):577-89. https://doi.org/10.1016/j.ja Iz.2015.10.009.

53. Staffaroni AM, Kramer AO, Casey M, Kang H, Rojas JC, Orrú CD, Caughey B, Allen IE, Kramer JH, Rosen HJ, Blennow K, Zetterberg H, Geschwind MD. Association of blood and cerebrospinal fluid tau level and other biomarkers with survival time in sporadic Creutzfeldt-Jakob disease. JAMA Neurol. 2019; 76(8):969-77. https://doi.org/10.1001/jamaneurol.2019.1071.

\section{Publisher's Note}

Springer Nature remains neutral with regard to jurisdictional claims in published maps and institutional affiliations.

Ready to submit your research? Choose BMC and benefit from:

- fast, convenient online submission

- thorough peer review by experienced researchers in your field

- rapid publication on acceptance

- support for research data, including large and complex data types

- gold Open Access which fosters wider collaboration and increased citations

- maximum visibility for your research: over $100 \mathrm{M}$ website views per year

At BMC, research is always in progress.

Learn more biomedcentral.com/submissions 